\title{
Transient Memory Impairment in Monkeys with Bilateral Lesions of the Entorhinal Cortex
}

\author{
Brian W. Leonard, ${ }^{1}$ David G. Amaral, ${ }^{1}$ Larry R. Squire, ${ }^{2}$ and Stuart Zola-Morgan ${ }^{2}$ \\ ${ }^{1}$ Center for Behavioral Neuroscience, University at Stony Brook, Stony Brook, New York 11794-2575 and ${ }^{2}$ Veterans \\ Affairs Medical Center, San Diego, and Departments of Psychiatry and Neurosciences, School of Medicine, \\ University of California, San Diego, California
}

\begin{abstract}
Performance on five behavioral tasks was assessed postoperatively in Macaca fascicularis monkeys prepared with bilateral lesions of the entorhinal cortex (E group). Three of the tasks were also readministered 9-14 months after surgery. Initial learning of the delayed nonmatching-tosample (DNMS) task was impaired in the $E$ animals relative to unoperated control monkeys. On the delay portion of DNMS, the performance of $E$ animals was nearly at control levels at short delays (up to $60 \mathrm{sec}$ ) but was impaired at 10 min and $\mathbf{4 0}$ min retention intervals. On the retest of DNMS, the $E$ animals performed normally at all retention intervals. The $E$ animals were unimpaired on the four other memory tasks. Neuroanatomical studies revealed a significant transverse expansion of the terminal field of the perirhinai cortical projection in the CA1 region of the hippocampus. Compared to unlesioned, anatomical control monkeys, the transverse length of the perirhinal terminal field in CA1 increased approximately $70 \%$ in the $E$ monkeys. Although this was a striking morphological alteration, it is not known whether the sprouting of this projection influenced the behavioral recovery. The results of these studies suggest that the entorhinal cortex may normally participate in the learning and performance of tasks that are dependent on the medial temporal lobe memory system. However, recovery of normal DNMS performance demonstrates that the entorhinal cortex is not, by itself, essential for learning and performance of such tasks.
\end{abstract}

[Key words: memory, hippocampus, amnesia, perirhinal cortex, behavioral recovery, nonhuman primate, medial temporal lobe, neuronal plasticity]

Bilateral damage to the human medial temporal lobe results in a profound and persistent anterograde amnesia (Scoville and Milner, 1957; Milner, 1972). Comprehensive neuropsychological and neuropathological studies of amnesic patients have provided

\footnotetext{
Received Dec. 5, 1994; revised March 9, 1995; accepted March 16, 1995. This work was supported in part by NIH Grants NS-16980 (D.G.A.), NS19063 (S.Z.-M.), NRSA 5 F32 NS09085-02 (B.W.L.), the Human Frontiers Science Program (D.G.A., L.R.S.), the Medical Research Service of the Department of Veterans Affairs, The Office of Naval Research, and The McKnight Foundation. We thank Cecelia LeClair, Amy Lockwood, Nancy Remple-Clower, and Lisa Stefanacci for surgical assistance, Janet Weber and Mary Ann Lawrence for histological assistance, and Kris Trulock for photographic assistance.

Correspondence should be addressed to David G. Amaral, Center for Behavioral Neuroscience, Psychology Building A, Third Floor, University at Stony Brook, Stony Brook, NY 11794-2575.

Copyright C 1995 Society for Neuroscience 0270-6474/95/155637-23\$05.00/0
}

substantial evidence that the hippocampal formation plays an essential role in normal memory function (Zola-Morgan et al., 1986; Victor and Agamanolis, 1990). Experimental support for this idea has also come from ablation studies in monkeys. These studies have identified several components of a medial temporal lobe memory system (Mishkin, 1978; see Squire and Zola-Morgan, 1991, for a review). The important structures appear to be the hippocampal formation itself (comprised of the dentate gyrus, hippocampus proper, subicular complex, and entorhinal cortex), and the adjacent perirhinal and parahippocampal cortices.

A major finding emerging from recent studics of the primate medial temporal lobe memory system is that structures other than those of the hippocampal formation play a significant role in normal memory function (Zola-Morgan and Squire, 1993; Mishkin and Murray, 1994). Combined lesions of the perirhinal and parahippocampal cortices, for example, which do not directly damage the hippocampal formation, impair memory performance nearly as severely as larger medial temporal lobe lesions that involve not only the perirhinal and parahippocampal cortices but the hippocampal formation and anyydala as well (Zola-Morgan et al., 1989b; Suzuki et al., 1993). This substantial effect of conjoint perirhinal and parahippocampal lesions is consistent with the findings from neuroanatomical studies that the perirhinal and parahippocampal cortices provide nearly twothirds of the neocortical input to the hippocampal formation (Insausti et al., 1987). These cortical regions are also a major route by which the hippocampal formation communicates with the neocortex (Suzuki and Amaral, 1994a). The question arises as to the relative contributions to normal memory function of these cortical areas and of the various divisions of the hippocampal formation. It was shown recently that lesions limited to the hippocampal region (defined as the dentate gyrus, hippocampus, and subicular complex-the $\mathrm{H}$ lesion), which spared the entorhinal cortex, produced a mild and enduring memory impairment that was less severe than was produced by damage to the perirhinal and parahippocampal cortices (Zola-Morgan et al., 1994; Alvarez et al., in press).

Given that most of the sensory information to the hippocampal formation enters via the entorhinal cortex (Van Hoesen and Pandya, 1975a,b; Van Hoesen et al., 1975; Insausti et al., 1987), and that the entorhinal cortex, which lies on the ventral surface of the brain, is a relatively easy target for selective ablation, we adopted the strategy of preparing animals with complete bilateral lesions of the entorhinal cortex. The question of interest is how monkeys with such lesions will compare to monkeys with $\mathrm{H}$ lesions, on the one hand, and monkeys with conjoint perirhinal 
and parahippocampal lesions, on the other hand. If the impairment resulting from damage to the perirhinal and parahippocampal cortices is due, in part, to a disconnection of the perirhinal and parahippocampal cortices from the hippocampal formation (i.e., to substantial loss of sensory information to the hippocampal formation), then damage to the entorhinal cortex should produce a substantial deficit, perhaps as severe as the perirhinal and parahippocampal lesion itself. Alternatively, if the perirhinal and parahippocampal cortices are themselves involved in visual recognition memory function, then lesions of the entorhinal cortex should result in a milder memory impairment.

\section{Materials and Methods}

Subjects. Twelve male Macaca fascicularis monkeys were used in these studies. The monkeys weighed 2.9 to $4.7 \mathrm{~kg}$ at the beginning of behavioral testing and were estimated to be young adults 3 to 5 years old (Hartley et al., 1984; Szabo and Cowan, 1984). The 12 monkeys were experimentally naive and belonged to two experimental groups. The entorhinal group (E) consisted of five monkeys who received bilateral aspiration lesions of the entorhinal cortex. The remaining seven monkeys comprised a normal unoperated control group $(\mathrm{N})$. Behavioral data from these seven animals have been reported previously (Zola-Morgan et al., 1992, 1993). Although the control group was not tested contemporaneously with the E group, the control animals received the battery of behavioral tests (see below) in the same order as the animals with lesions, and they were tested in the same laboratory using the same apparatus and test protocols.

All monkeys were maintained on a $12 \mathrm{hr}$ on:12 hr off light:dark schedule and were fed a daily ration of Purina Monkey Chow that was supplemented once each week with fruit. A research protocol describing all aspects of the present study (care, maintenance, surgery, behavioral testing, anatomical experiments, and euthanasia) was approved by the Animal Subjects Committee of the University of California, San Diego.

Monkeys used for anatomical analyses. In addition to the monkeys used for the behavioral portion of these studies, five additional male $M$. fascicularis monkeys served as control subjects for quantitative analyses of the entorhinal cortical lesions. Because the size of the entorhinal cortex in $M$. fascicularis monkeys is roughly correlated with body weight (Suzuki and Amaral, unpublished observations), we selected histological control tissue that came from animals of similar weights to those with the entorhinal lesions. The body weights of the five $\mathrm{E}$ animals at the time of death were $5.2 \mathrm{~kg}, 5.4 \mathrm{~kg}, 5.5 \mathrm{~kg}, 5.6 \mathrm{~kg}$, and 7.1 $\mathrm{kg}$. The body weights of the five histological control animals were 3.9 $\mathrm{kg}, 4.0 \mathrm{~kg}, 4.5 \mathrm{~kg}, 4.9 \mathrm{~kg}$, and $5.2 \mathrm{~kg}$. There was no histological control animal available to match the largest $\mathrm{E}$ animal. Most of the neuroanatomical control monkeys had been used in separate neuroanatomical studies involving small tracer injections into the medial temporal lobe. Histological processing of the brains from the E group and the neuroanatomical control animals was carried out in the same laboratory using similar procedures for both groups. For quantitative comparisons of anterograde tracer injection experiments conducted in the $\mathrm{E}$ animals at the conclusion of behavioral experiments (see below), autoradiographic material from five additional neuroanatomical control monkeys was used. Separate analyses from these monkeys, identified as DM-42, M-1-88, M-7-91, M-12-91, and M-1-92, have appeared in Suzuki and Amaral (1994a). In addition, autoradiographic material was available from an entorhinal-lesioned monkey (identified as E-315) that was eliminated from behavioral testing due to motivational problems. This monkey's lesion was similar in extent and selectivity to that in monkey E5, and the injection of ${ }^{3} \mathrm{H}$-amino acids was appropriately placed in the perirhinal cortex (see below). The brain of this animal therefore was included in the quantitative analysis.

Surgery. A direct visual approach was used to produce the entorhinal lesions. The location and extent of the intended lesion is shown as hatching in Figure 1. The general surgical approach and surgical procedures have been described in detail elsewhere (Zola-Morgan et al., 1993). Briefly, animals were preanesthetized with ketamine hydrochloride $(10 \mathrm{mg} / \mathrm{kg}$, i.m. $)$ and administered atropine $(0.05 \mathrm{mg} / \mathrm{kg}$, i.m. $)$, intubated with a tracheal cannula, and mounted in a custom-designed head holder, which allowed unobstructed access to the temporal portion of the skull. Animals were subsequently maintained at a surgical level of anesthesia with a mixture of isoflurane (1-2\% Furane) and oxygen gases. The vital signs of the animals were continuously monitored through-

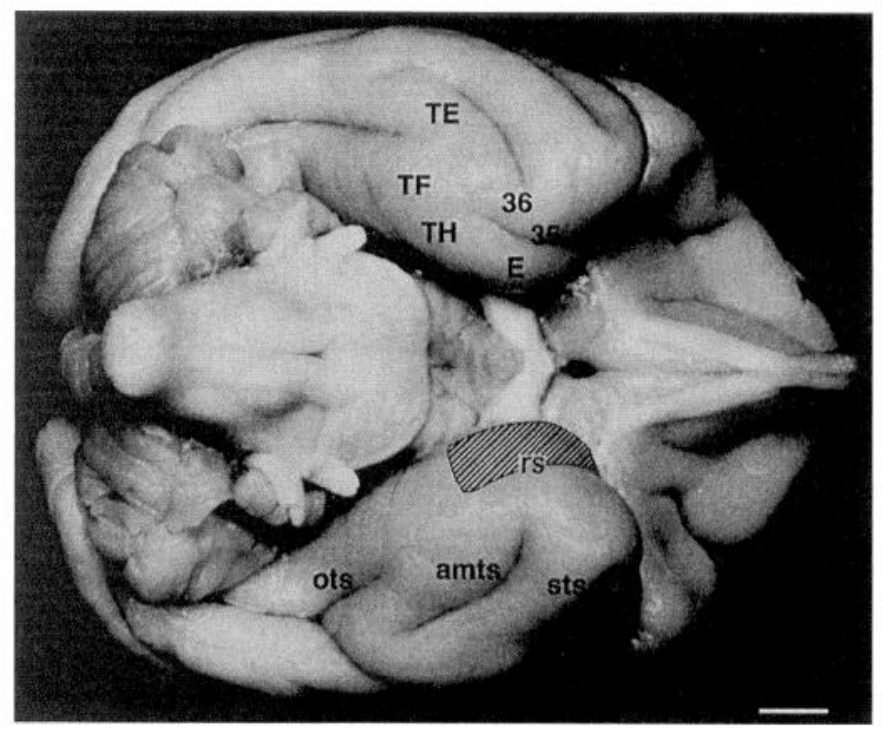

Figure 1. Ventral view of the Macaca fascicularis monkey brain showing the approximate location of the entorhinal cortex $(E$, hatched area) and its relationship to other temporal cortical regions. Abbreviations: amts, anterior middle temporal sulcus; ots, occipital temporal sulcus; $r s$, rhinal sulcus; sts, superior temporal sulcus; $T E, T F, T H$, fields of von Bonin and Bailey (1947); 35, 36, fields of the perirhinal cortex (Brodmann) after Amaral et al. (1987) and Suzuki and Amaral (1994a,b). Scale bar, $5 \mathrm{~mm}$.

out surgery and used as indicators for modification of the level of anesthesia. The temporal muscles were deinserted from their origin on the temporal fossa and reflected to reveal the temporal and sphenoid bones. The zygomatic arches were removed to provide a better exposure of the ventrolateral aspect of the skull. Bilateral craniotomies were then made over the anterior temporal lobe. Under direct visual control, the dura mater was opened in a pie-shaped fashion and the temporal lobe was gently elevated to reveal the entorhinal cortex. The entorhinal cortex was considered to be bounded laterally by the rhinal sulcus, medially by the sulcus semiannularis (rostrally) and the choroidal fissure (caudally). We attempted to remove tissue medial to the rhinal sulcus as far rostrodorsally into the temporal pole as possible. The caudal border of the entorhinal cortex was taken to lie approximately $1 \mathrm{~mm}$ caudal to the caudal limit of the rhinal sulcus. The pia at the borders of the entorhinal cortex was cauterized and then the entire surface of the entorhinal cortex was cauterized. At this point, the cauterized cortical tissue was aspirated, purposely sparing the underlying white matter. We also attempted to refrain from entering the rhinal sulcus in order to leave as much of the perirhinal cortex intact as possible. Once hemostasis was achieved, the surgery was completed by suturing the dura mater and closing the wound in layers. Animals were placed into warmed chambers and carefully monitored postoperatively until they were fully recovered. Prophylactic antibiotics and postoperative analgesics were administered according to the recommendations of consulting veterinary staff. Monkeys were allowed to recover approximately 12 weeks before behavioral testing was begun.

Behavioral testing. All behavioral training and testing was carried out postoperatively. Testing was conducted $5 \mathrm{~d}$ per week in a Wisconsin General Test Apparatus (WGTA) (Harlow and Bromer, 1938) during the animals' light phase. Before formal testing began, monkeys were first trained to displace junk objects that covered raisin rewards in the three food wells of the WGTA. Pretraining typically required six to eight daily sessions, and formal testing began immediately thereafter.

Five different tasks (described in detail in Zola-Morgan and Squire, 1985), and retests of four of the tasks, were administered in the following order: (1) visual trial-unique delayed nonmatching to sample (DNMS-I); (2) two-dimensional pattern discrimination; (3) delayed retention of object discriminations; (4) eight-pair concurrent object discrimination; (5) retest of delayed nonmatching to sample (DNMS-II); (6) lifesaver motor skill task; (7) retest of object discriminations; (8) retest of eight-pair concurrent object discrimination; (9) retest of lifesaver motor skill. Animals were tested continuously and typically had 


\section{Normal EC}
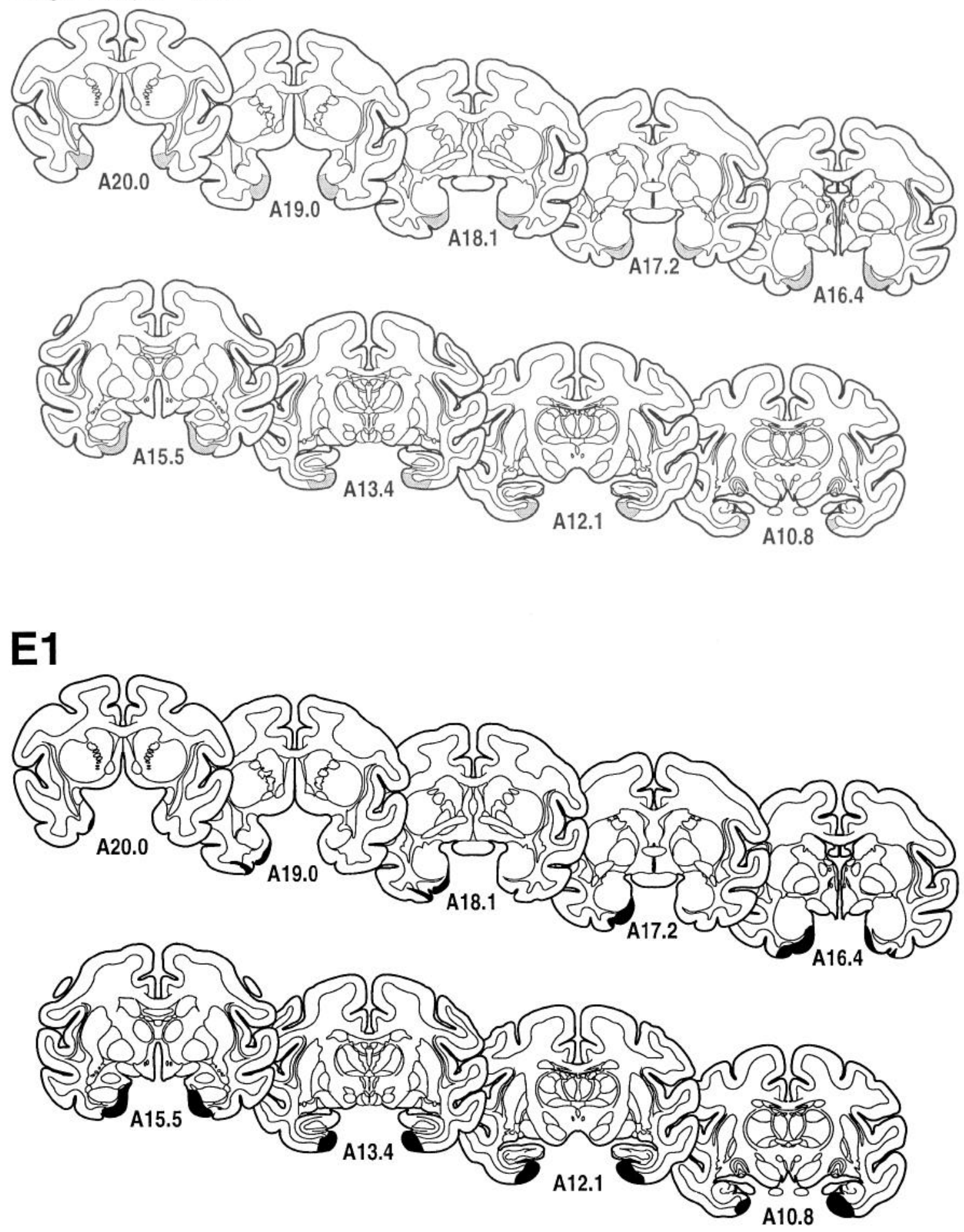

Figure 2. Representative coronal sections (adapted from Szabo and Cowan, 1984) through the brain of a normal unlesioned monkey (Normal EC) and the brains of the five experimental monkeys $(E 1-E 5)$ with bilateral entorhinal lesions. The full extent of the entorhinal cortex is indicated with light shading in the Normal animal. The extents of the lesions, based on microscopic analysis of Nissl-stained sections, are plotted as blackened areas on the series of coronal sections for each animal. The rostrocaudal level is indicated below each section.

periods of 1 week or less interposed between testing on different tasks. The five tasks were administered as described previously (Zola-Morgan and Squire, 1984, 1985; Zola-Morgan et al., 1993) with the following additions. For the delay portion of DNMS-I and DNMS-II, 50 trials were also administered at a $40 \mathrm{~min}$ retention interval. For the retest of object discriminations, each object pair was tested on a single day for
20 trials. The four discriminations were retested in the same order that they had been presented originally. For the retest of concurrent object discrimination, animals were tested until they reached a $90 \%$ correct learning criterion. Other details of the tests are given in the Results section. Three of the control animals (N5-N7) were not tested on the 40 min delay of DNMS-I or DNMS-II, the retest of object discrimina- 
E2
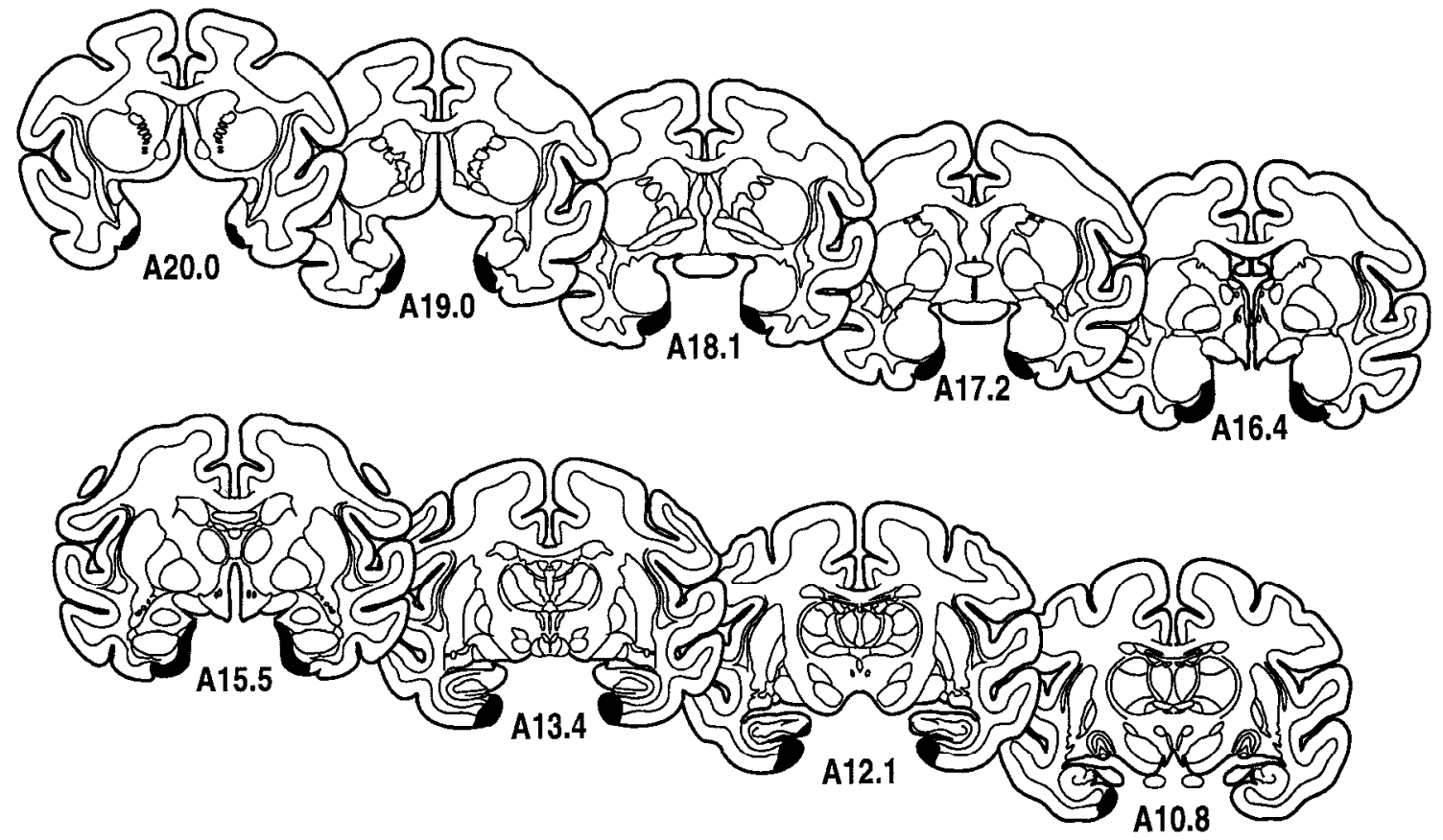

E3
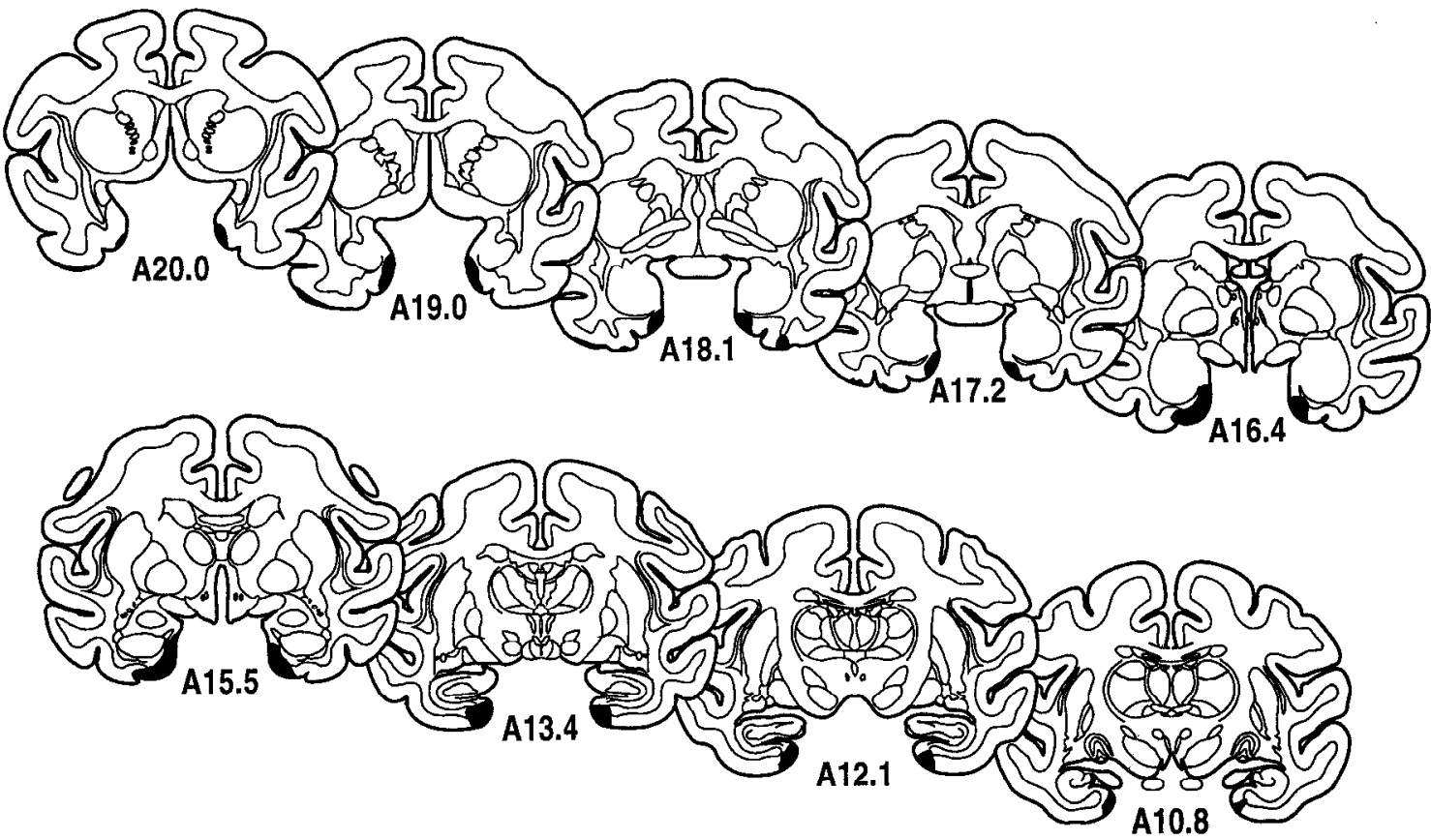

Figure 2. Continued.

tions, or the retest of eight-pair concurrent object discrimination. One animal in the E group (E5) was not tested on the lifesaver motor skill task or on the retest of the eight-pair concurrent object discrimination task.

Neuroanatomical studies. At the conclusion of behavioral testing of the $\mathrm{E}$ group, we employed neuroanatomical techniques to examine the status of the remaining afferent connections of the hippocampal formation. These studies were intended to determine whether residual entorhinal cortex retained connections with the dentate gyrus and hippo- campus, and to obtain evidence for the patency of normal projections from the perirhinal and parahippocampal cortices (and other cortical regions) to the CA1/subiculum region of the hippocampal formation. Injections of the retrograde tracers Fast blue (FB) and diamidino yellow (DY) were aimed at two different rostrocaudal levels of the hippocampus/subiculum border and dentate gyrus in one hemisphere of each animal (see below). Based on earlier topographic studies of the perforant path projection, we expected that these injections should lead to labeling of much of the surface of the entorhinal cortex, particularly of its most 

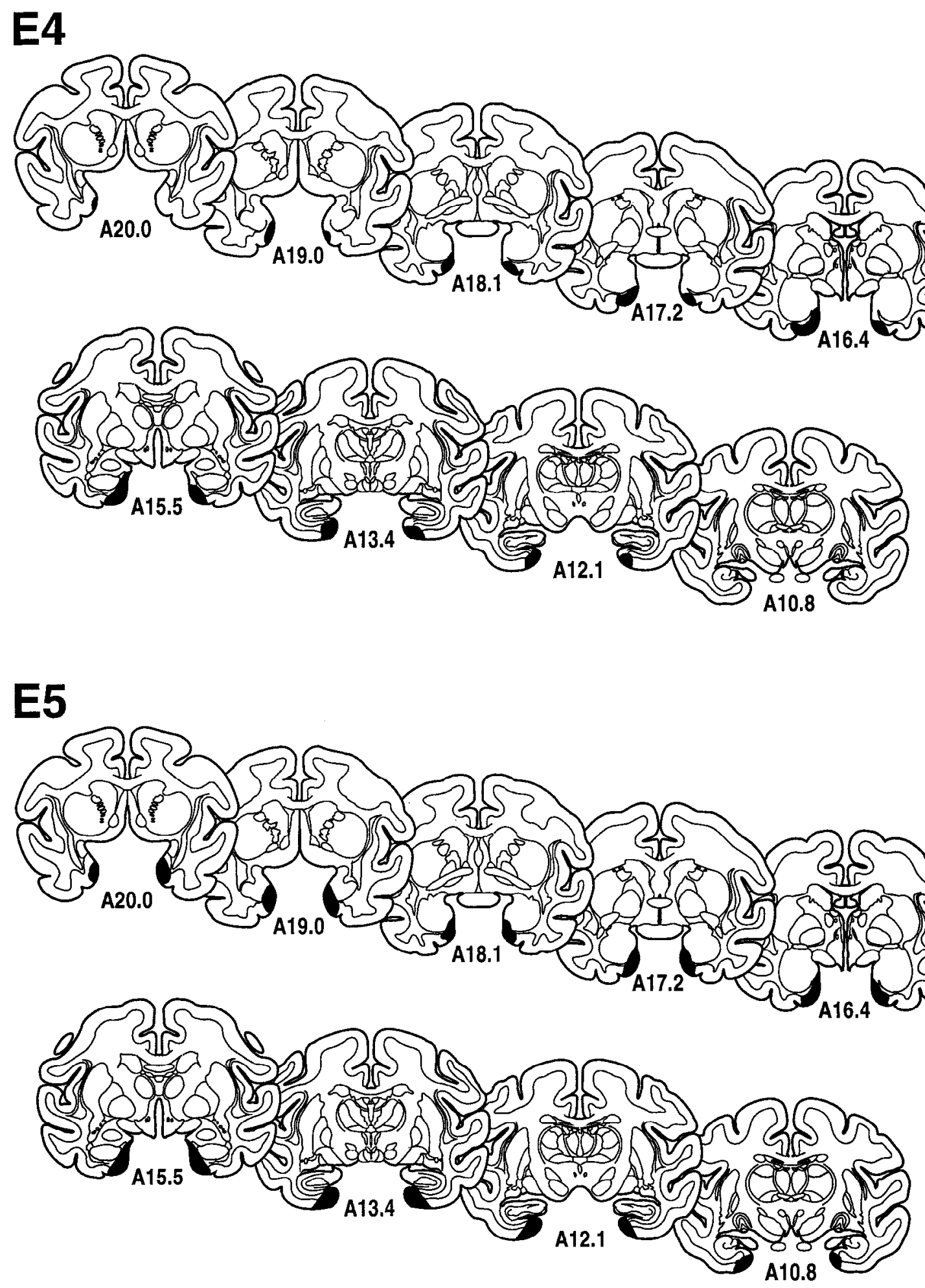

Figure 2. Continued.

lateral aspect (Witter et al., 1989; Witter and Amaral, 1991). In addition, we explored whether denervation-induced sprouting of direct perirhinal cortical projections to the hippocampus (Kosel et al., 1983; Suzuki and Amaral, 1990) might be related to the behavioral recovery we observed in the E group. To examine this possibility, we aimed in each animal a $100 \mathrm{nl}$ injection of an amino acid cocktail of ${ }^{3} \mathrm{H}$-proline and ${ }^{3} \mathrm{H}$-leucine (concentrated to $100 \mu \mathrm{Ci} / \mu \mathrm{l}$ ) at the perirhinal cortex contralateral to the hemisphere in which the FB and DY injections were placed.

To obtain more accurate placement of the tracers, each experimental animal was first studied with magnetic resonance imaging (MRI), and individual MRI brain "atlases" were prepared as described by AlvarezRoyo et al. (1991). From these atlases, skull and depth coordinates were derived for five injection sites in each animal. These were (1) rostral hippocampal C.A1-subiculum; (2) rostral dentate gyrus (at the same A-P level as 1); (3) midrostral-caudal hippocampal CA1-subiculum; (4) midrostral-caudal dentate gyrus (at the same A-P level as 3); and (5) midrostral-caudal perirhinal cortex (medial arca 36). Five hundred nanoliters of 3\% FB was deposited at the rostral hippocampus/subiculum and 
HISTOLOGICAL CONTROLS
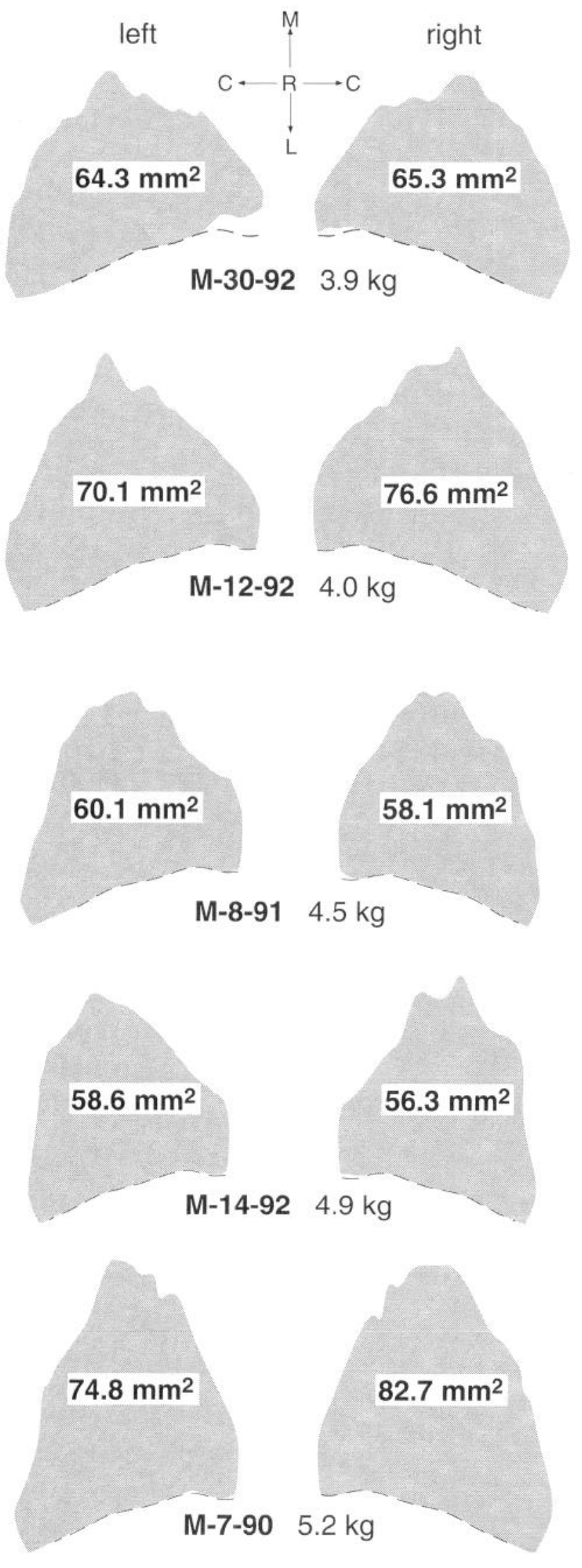

\section{ENTORHINAL GROUP}

left<smiles>[M][Pb](C)(C)CC</smiles>

right

\section{E $25.2 \mathrm{~kg}$}

$11.5 \mathrm{~mm}^{2}$
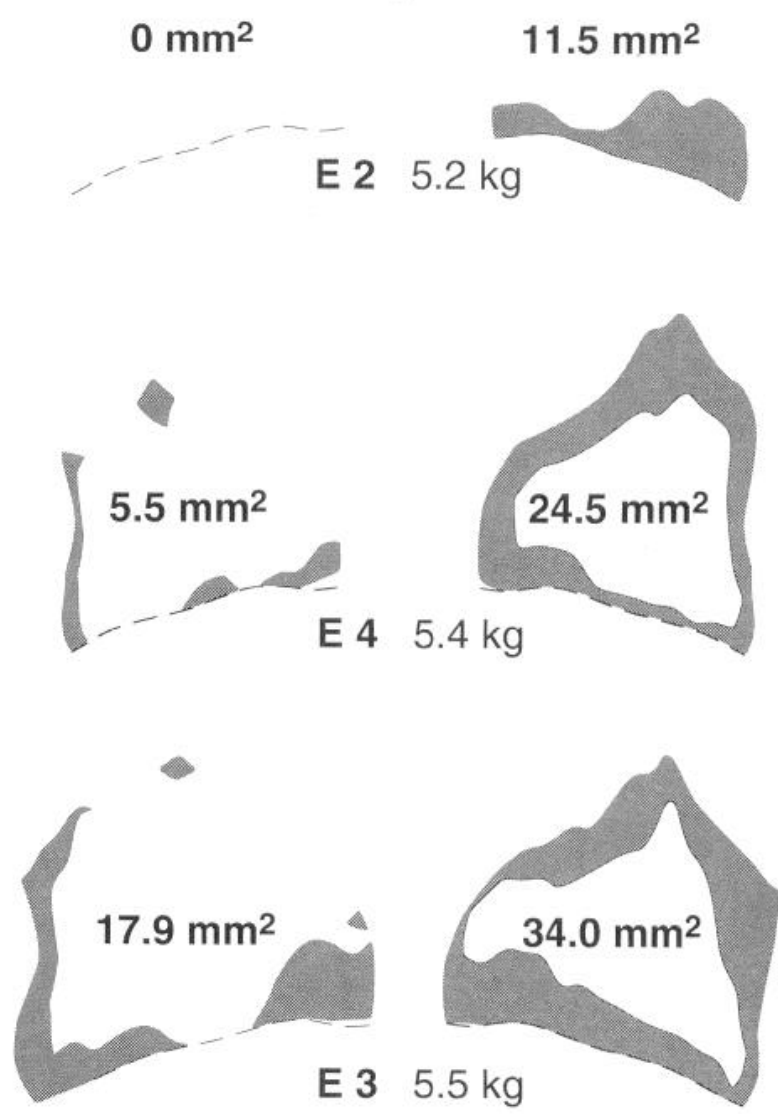

$2.3 \mathrm{~mm}^{2}$

$2.0 \mathrm{~mm}^{2}$

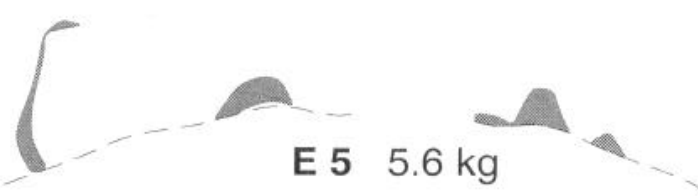

$1.7 \mathrm{~mm}^{2}$

$13.2 \mathrm{~mm}^{2}$

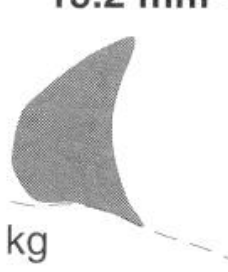


dentate gyrus sites, $1000 \mathrm{nl}$ of $2 \%$ DY was deposited at the caudal hippocampus/subiculum site, and $500 \mathrm{nl}$ of $2 \%$ DY was deposited at the caudal dentate gyrus site. Surgical and injection procedures for the tracer experiments have been described in detail elsewhere (Suzuki and Amaral, 1994a,b). The postinjection survival time was $14 \mathrm{~d}$.

Perfusions and histological preparation. Animals were preanesthetized with ketamine hydrochloride $(10 \mathrm{mg} / \mathrm{kg}$, i.m.) and subsequently given a lethal dose of sodium pentobarbital $(50 \mathrm{mg} / \mathrm{kg}$, i.p.). Upon elimination of the corneal reflex, animals were transcardially perfused with the following ice-chilled solutions for the corresponding times and rates: (1) $1 \%$ paraformaldehyde in $0.1 \mathrm{M}$ phosphate buffer for $1 \mathrm{~min}$ at 250 $\mathrm{ml} / \mathrm{min}$; (2) $4 \%$ paraformaldehyde in $0.1 \mathrm{M}$ phosphate buffer for $10 \mathrm{~min}$ at $250 \mathrm{ml} / \mathrm{min}$; (3) $4 \%$ paraformaldehyde in $0.1 \mathrm{M}$ phosphate buffer for $50 \mathrm{~min}$ at $100 \mathrm{ml} / \mathrm{min}$; (4) $5 \%$ sucrose in $0.1 \mathrm{M}$ phosphate buffer for $20 \mathrm{~min}$ at $100 \mathrm{ml} / \mathrm{min}$. The descending aorta was clamped and the head was packed in crushed ice throughout the perfusion. The brains were partially blocked in situ in the coronal plane, carefully extracted from the cranium, and stored initially in a $10 \%$ solution of glycerol in $0.1 \mathrm{M}$ phosphate buffer. The ventral surface of the brain was documented photographically, after which the brain was stored for $1 \mathrm{~d}$ in a solution of $10 \%$ glycerol with $2 \%$ DMSO in $0.1 \mathrm{M}$ phosphate buffer at $4^{\circ} \mathrm{C}$. The brains were then transferred to a solution of $20 \%$ glycerol with $2 \%$ DMSO in $0.1 \mathrm{M}$ phosphate buffer, where they remained at $4^{\circ} \mathrm{C}$ for $3 \mathrm{~d}$. Finally, the brains were frozen in isopentane chilled to $-78^{\circ} \mathrm{C}$. The brains were stored at $-74^{\circ} \mathrm{C}$ until they were sectioned.

Sections $30 \mu \mathrm{m}$ thick were cut in the coronal plane through the frontal and temporal lobes using a freezing microtome. Two 1 -in- 10 series of sections were mounted immediately onto gelatin-coated slides for analysis of the distribution of FB and DY retrogradely labeled neurons (see below). Two other series of sections were collected in $10 \%$ formalin in $0.1 \mathrm{M}$ phosphate buffer; one was used for Nissl staining, and one was used for autoradiographic analysis of transported tritiated amino acids (see below). An additional series was collected in sodium acetate buffer for $\mathrm{AChE}$ histochemical staining. The remaining series were collected in a cryoprotectant solution and stored at $-74^{\circ} \mathrm{C}$. The mounted sections designated for fluorescent dye analyses were quickly air dried and stored in darkness in desiccated containers at $-20^{\circ} \mathrm{C}$. The Nissl series used for the lesion analysis was adjacent to the two fluorescent dye series. These sections were postfixed in $10 \%$ formalin in $0.1 \mathrm{M}$ phosphate buffer for at least 2 weeks, rinsed with phosphate buffer, mounted on gelatin-coated slides, defatted, stained with $0.25 \%$ Thionin, dehydrated, cleared, and coverslipped. The sections used for autoradiographic demonstration of anterogradely transported isotope were processed according to the protocol described in Suzuki and Amaral (1994a) with exposure time of 10 weeks.

Lesion evaluation. Initially, the Nissl-stained sections through the entorhinal cortex were examined qualitatively to assess the extent of the lesions in each experimental animal. To achieve a more quantitative estimate of the extent of the lesion, "unfolded maps" of the entorhinal cortex (as described more fully in Amaral et al., 1987) were constructed following the procedures of Van Essen and Maunsell (1980). Bilateral maps were constructed for the animals with entorhinal lesions and for the histological control animals. It was often the case that tissue in the region of the entorhinal cortex would be present but essentially devoid of healthy looking cells. For spared entorhinal cortex to be included in an unfolded entorhinal map, layer II entorhinal neurons had to be clearly present in the Nissl-stained material. The presence or absence of FBand DY-labeled layer II entorhinal neurons resulting from the hippocampus/dentate gyrus injections provided additional information on which to base these decisions. Based on previous studies of the topo- graphical organization of the perforant path projection (Witter et al., 1989), it was expected that the fluorescent dye injections would retrogradely label much of the transverse and rostrocaudal extents of layer II of the entorhinal cortex; the injections would particularly favor labeling of the most lateral portions of the entorhinal cortex. To obtain a more quantitative measure of the completeness of the lesions, the surface areas of the entorhinal maps were measured using a commercially available digitizing tablet and associated tracing software (Sigma-Scan, Jandel Scientific). In addition to evaluating directly the areal extent of the lesions, we also calculated the average area of the molecular layer of the dentate gyrus. Loss of the perforant path was predicted to lead to a shrinkage of the molecular layer of the dentate gyrus in which it terminates. Five identifiable rostrocaudal levels of the dentate gyrus were selected, and camera lucida drawings were made of the molecular layer of the dentate gyrus from these levels for both the histological control animals and the $\mathrm{E}$ animals. The cross-sectional areas of the molecular layers in these sections were measured with the digitizing tablet described above.

Analyses of tracer experiments. The sections prepared for fluorescent dye analysis were examined with a Leitz Dialux 20 fluorescent microscope interfaced to a commercially available digitizing and plotting computer system (MD-2, Minnesota Datametrics). Slides from one series of the fluorescent material were coverslipped using buffered glycerol and viewed with a $20 \times$ objective. The distributions of FB- and DY-labeled neurons were plotted at a rostrocaudal sampling interval of $1.2 \mathrm{~mm}$, starting from the prefrontal cortex and ending at the caudal pole of the hippocampal formation. For some animals, a smaller sampling interval was used through the entorhinal cortex.

Quantitative comparisons of the terminal field of the perirhinal-to-hippocampal projections in the $\mathrm{E}$ animals were made using material from a library of anatomical experiments in which tritiated amino acid injections were placed in the perirhinal cortex of normal control monkeys (Suzuki and Amaral, 1994a,b). Five identifiable rostrocaudal levels of the hippocampus were selected, and camera lucida drawings were made of the hippocampal and subicular fields for both the anatomical control monkeys and the E monkeys. Under dark-field illumination, the extent of the terminal field was added to these drawings. Radial and transverse measures of the terminal field and of the entire stratum lacunosum-moleculare were collected using the digitizing tablet described above. The radial distance of the stratum lacunosum-moleculare was measured at the CA1-CA2 border, CAl-subicular border, and half-way between these two borders. The combined radial distance of stratum lacunosum-moleculare and stratum radiatum at these three points was also measured to obtain a relative measure of the width of stratum lacunosum-moleculare. Secondly, the transverse distance of the terminal field and of the entire stratum lacunosum-moleculare was measured along the border between stratum lacunosum-moleculare and stratum radiatum, starting at the CA1/subiculum border and ending at the CA1-CA2 border.

\section{Results}

\section{Histological findings}

Figure 1 illustrates the position of the entorhinal cortex on the ventromedial portion of the temporal lobe of the Macaca fascicularis monkey brain. Figure 2 shows line drawings of representative coronal sections (adapted from Szabo and Cowan, 1984) through the rostrocaudal extent of the entorhinal cortex. The location of the entorhinal cortex (intended lesion) in an unlesioned animal (Normal EC) and the extent of lesions in each

\section{$\leftarrow$}

Figure 3. Unfolded two-dimensional bilateral maps of the entorhinal cortex of five histological control monkeys and the spared entorhinal cortex of experimental monkeys E1-E5. Body weights are indicated next to animal number. Maps are based on the pial surface. For monkeys E1-E5, the unlesioned portions of entorhinal cortex are shown in gray. Dashed lines represent the rhinal sulcus (rs). Numbers on maps indicate the total unilateral area $\left(\mathrm{mm}^{2}\right)$ of entorhinal cortex. $R, C, M$, and $L$ refer to rostral, caudal, medial and lateral, respectively. Scale bar, $1 \mathrm{~mm}$.

Figure 4. Photomicrographs of representative coronal sections through the left and right medial temporal lobe of monkey E5. Sections are arranged from rostral $(A)$ to caudal $(F)$. The extent of the lesion in each section is bracketed by arrowheads. The open arrow in panel $E$ (left) points to the core of the Fast blue injection, and the open arrow in panel $F$ (right) points to the location of the ${ }^{3} \mathrm{H}$-amino acid injection into area 36 . Asterisks indicatc artifacts duc to histological processing. Additional abbreviations: $A$, amygdala; $H$, hippocampus; $V$, ventricle; 35 , 36r, 36c, ficlds of the perirhinal cortex after Amaral et al. (1987). Scale bar, $1 \mathrm{~mm}$. 



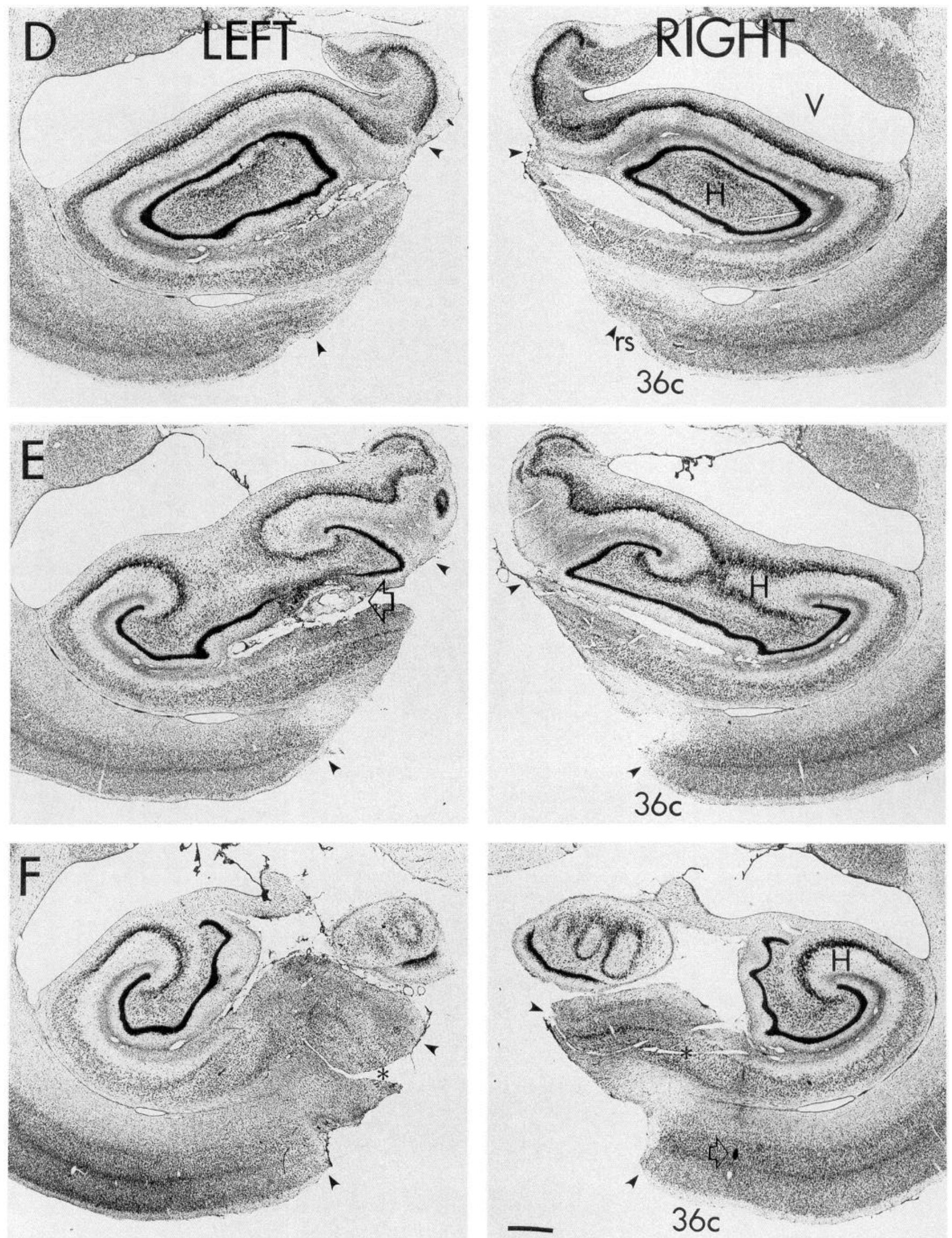
experimental animal are also illustrated. To represent the total surface area of the entorhinal cortex that was spared in E group animals, two-dimensional unfolded maps of the spared entorhinal cortex were constructed ( $\Gamma i g$. 3). For comparison, unfolded maps were also prepared from five normal monkeys that were of approximately similar weights as the $\mathrm{E}$ group animals. The full rostrocaudal extent of the lesion in animal E5 is shown in a series of photomicrographs in Figure 4 . The following summarizes the extents of the lesions in each of the animals. In each case, the lesion in the left hemisphere is described first, followed by a description of the right hemisphere; the overall extent of the lesion is then briefly summarized.

Monkey E1. The lesion in this animal begins slightly more rostrally on the left side than on the right. It began on the left as a thinning of layer 1 of the ventral periamygdaloid cortex. The damage expanded rapidly at more caudal levels and included all layers of the cortex for much of the rostrocaudal and mediolateral extents of the entorhinal cortex. At the rostral pole, a narrow $(\approx 1 \mathrm{~mm}$ ) portion of the laterally situated entorhinal cortex, occupying the medial bank of the rhinal sulcus, appeared somewhat intact in the Nissl preparations. It was included in the unfolded map because a few retrogradely labeled neurons were present in this area. Here, and throughout the remainder of these descriptions, the lack of retrogradely labeled cells in spared entorhinal cortex in cases with appropriately placed injections (as in this case), is taken as additional evidence that the remaining neurons have lost their connection with the hippocampal formation. At more caudal levels of the entorhinal cortex, the medial bank of the rhinal sulcus was either completely obliterated by the lesion, or contained only a few scattered layer II and III neurons. Again, this latter observation was confirmed by the lack of retrogradely labeled cells. Caudal to the rhinal sulcus, the entorhinal cortex was eliminated except for a patch $(\approx 1 / 2 \mathrm{~mm}$ in rostrocaudal extent) of marginally intact layer II and 111 entorhinal neurons at the caudal border of the entorhinal cortex. A fcw of the ncurons in this region were retrogradely labcled.

A small amount of unintended damage was observed in the left hemisphere. The lesion encroached slightly on the ventromedial amygdala rostrally and invaded the distal subicular complex caudally, although the subiculum proper was only slightly involved. The angular bundle was mostly transected at the level of the rostral hippocampus. The perirhinal cortex of the left henisphere was largely intact, except for a small region at the level of the rostral third of the amygdala that was damaged by an infarct. This infarct produced a narrow band of necrosis that was oriented obliquely and that extended laterally from the rhinal sulcus to the deep layers of area TE. The infarct involved areas 35, 36, and medial TE (Fig. 2, E1-A16.4). The parahippocampal cortex was intact on the left side.

The lesion on the right side was smaller than on the left, and a significant amount of rostral entorhinal cortex remained intact. The spared entorhinal cortex began at its rostral boundary and extended for about $2.4 \mathrm{~mm}$ caudally. The lesion began abruptly at about the midamygdaloid level just ventral to the sulcus semiannularis and expanded ventrolaterally in the caudal direction to include all layers of the entorhinal cortex. As in the left hemisphere, a substantial part of the distal subicular complex was damaged by the lesion but there was less damage to the subiculum and presubiculum than on the left side. The caudal pole of the entorhinal cortex was completely removed by the lesion, which also extended slightly into the superficial layers of the rostral parahippocampal cortex. Although the lateral bank of the rhinal sulcus was intact throughout most of its extent, the lesion did extend laterally to the rhinal sulcus and involved a portion of area 36. The rostrocaudal extent of this damage was about $2.4 \mathrm{~mm}$ and began in the caudal portion of ared 36r and extended into the rostral portion of $36 \mathrm{c}$. As with the left side, the angular bundle was transected near the rostral pole of the hippocampus.

In summary, in animal E1, the entorhinal cortex was substantially damaged bilaterally. On the left side, approximately 1.7 $\mathrm{mm}^{2}$ of spared entorhinal tissue remained, and on the right side, there was $13.2 \mathrm{~mm}^{2}$ of spared entorhinal cortex. Taken together therefore a total of $14.9 \mathrm{~mm}^{2}$ of entorhinal cortex remained unlesioned in monkey E1. Because the average bilateral surface area of the normal histological control animals was $133.4 \mathrm{~mm}^{2}$, there was a loss of $89 \%$ of the entorhinal cortex in animal E1. Although the lesion was somewhat asymmetrical, most of the middle and caudal portions of the entorhinal cortex of both hemispheres was removed. Moreover, there were very few retrogradely labeled cells in the apparently spared entorhinal cortex in the left hemisphere. The scarcity of retrogradely labeled cells is likely due to the fact that the fibers originating from these cells were transected by direct damage to the angular bundle. We cannot directly evaluate whether the spared entorhinal cortex of the right hemisphere maintained patent connections with the hippocampus and dentate gyrus (retrograde tracers were placed only in the left hemisphere). However, because the angular bundle was also transected, it is likely that the remaining entorhinal cortex was largely disconnected from the dentate gyrus and hippocampus. Besides the angular bundle damage, the only substantial bilateral extra-entorhinal damage in animal E1 occurred in the distal portions of the subicular complex. This unintended damage involved primarily the presubiculum and parasubiculum.

Monkey E2. The lesion in this animal was more extensive and bilaterally symmetrical than in animal E1. However, the brain of this animal demonstrated significant hydrocephalus in the rostral region of the left lateral ventricle and the consequent distortion of brain tissue complicated the assessment of lesioninduced damage on the left side. The lesion in the left hemisphere began abruptly just in front of the rostral pole of the entorhinal cortex. Here, the lesion involved the ventral portion of the periamygdaloid cortex and the ventromedial amygdala. Area 35 appeared intact at this level. The lesion widened as it extended caudally to include all layers of the entorhinal cortex. It was restricted to areas located medial to the rhinal sulcus for its entire rostrocaudal extent. In the regions where the rhinal sulcus was identifiable, only the fundus and lateral bank were present. As with animal E1, the lesion also involved the distal subicular complex, mostly damaging the pre- and parasubiculum. For a short distance $(\approx 1.2 \mathrm{~mm}$ ) this part of the lesion resulted in a punctate region of dentate granule cell loss in the medial crest of the dentate gyrus. The caudal extreme of the lesion extended slightly into the superficial cell layers of the parahippocampal cortex. The most medial part of caudal arca 36 was slightly involved by the lesion for about $4 \mathrm{~mm}$, starting approximately at the genu of the hippocampus. As with animal $\mathrm{E} 1$, the medial portion of the angular bundle was transected in the region of the rostral hippocampus.

The lesion on the right side began at about the same level as on the left side but did not extend as far caudally. Again, the lesion began abruptly and included a small portion of the ventral periamygdaloid cortex. The remainder of the amygdala was intact. The lesion on the right side did not extend as far laterally, and the most lateral aspect of the entorhinal cortex (approxi- 
Table 1. Individual performance on delayed nonmatching to sample (DNMS)

\begin{tabular}{|c|c|c|c|c|c|c|c|c|c|c|c|c|c|c|c|c|}
\hline \multirow[b]{3}{*}{ Group } & \multicolumn{8}{|l|}{ DNMS-I } & \multicolumn{8}{|l|}{ DNMS-II } \\
\hline & \multirow[b]{2}{*}{$\begin{array}{l}\text { Trials to } \\
\text { criterion }^{a}\end{array}$} & \multicolumn{7}{|c|}{ Delays (\% correct) } & \multirow[b]{2}{*}{$\begin{array}{l}\text { Trials to } \\
\text { criterion }^{a}\end{array}$} & \multicolumn{7}{|c|}{ Delays ( $\%$ correct) } \\
\hline & & $\begin{array}{l}8 \\
\text { sec }\end{array}$ & $\begin{array}{l}15 \\
\text { sec }\end{array}$ & $\begin{array}{l}60 \\
\sec \end{array}$ & $\begin{array}{l}10 \\
\min \end{array}$ & $\begin{array}{l}40 \\
\min \end{array}$ & $\begin{array}{l}\text { Mean } \\
15 / 60 / 10 \\
\end{array}$ & $\begin{array}{l}\text { Mean } \\
15 / 60 / 10 / 40 \\
\end{array}$ & & $\begin{array}{l}8 \\
\text { sec }\end{array}$ & $\begin{array}{l}15 \\
\mathrm{sec}\end{array}$ & $\begin{array}{l}60 \\
\text { sec }\end{array}$ & $\begin{array}{l}10 \\
\text { min }\end{array}$ & $\begin{array}{l}40 \\
\text { min }\end{array}$ & $\begin{array}{l}\text { Mean } \\
15 / 60 / 10\end{array}$ & $\begin{array}{l}\text { Mean } \\
15 / 60 / 10 / 40\end{array}$ \\
\hline \multicolumn{17}{|l|}{ Normal } \\
\hline 1 & 180 & 90 & 95 & 86 & 80 & 73 & 87 & 84 & 0 & 94 & 91 & 90 & 66 & 76 & 82 & 81 \\
\hline 2 & 440 & 91 & 91 & 90 & 64 & 62 & 82 & 77 & 0 & 93 & 96 & 97 & 76 & 76 & 90 & 86 \\
\hline 3 & 220 & 90 & 91 & 85 & 76 & 62 & 84 & 78 & 0 & 92 & 94 & 90 & 82 & 82 & 89 & 87 \\
\hline 4 & 120 & 91 & 98 & 93 & 83 & 68 & 91 & 86 & 20 & 92 & 95 & 89 & 82 & 84 & 89 & 87 \\
\hline $5^{b}$ & 180 & 90 & 95 & 85 & 80 & - & 87 & - & 0 & 92 & 93 & 84 & 70 & - & 82 & - \\
\hline $6^{b}$ & 160 & 90 & 96 & 97 & 80 & - & 91 & - & 0 & 93 & 90 & 93 & 86 & - & 90 & - \\
\hline $7^{b}$ & 80 & 90 & 92 & 89 & 92 & - & 91 & - & 80 & 91 & 76 & 86 & 80 & - & 81 & - \\
\hline Mean & 197 & 90 & 94 & 89 & 79 & 66 & 88 & 81 & 14 & 92 & 91 & 90 & 77 & 80 & 86 & 85 \\
\hline \multicolumn{17}{|l|}{ Entorhinal } \\
\hline 1 & 1030 & 91 & 87 & 79 & 54 & 52 & 73 & 68 & 0 & 90 & 85 & 88 & 64 & 54 & 79 & 73 \\
\hline 2 & 562 & 92 & 95 & 89 & 72 & 56 & 85 & 78 & 0 & 95 & 95 & 92 & 86 & 64 & 91 & 84 \\
\hline 3 & 377 & 90 & 96 & 81 & 64 & 58 & 80 & 75 & 0 & 94 & 95 & 90 & 78 & 72 & 88 & 84 \\
\hline 4 & 540 & 90 & 93 & 89 & 60 & 60 & 81 & 76 & 0 & 93 & 95 & 93 & 92 & 84 & 93 & 91 \\
\hline 5 & 274 & 90 & 80 & 86 & 64 & 55 & 77 & 71 & 294 & 92 & 89 & 80 & 74 & 76 & 81 & 80 \\
\hline Mean & 557 & 91 & 90 & 85 & 63 & 56 & 79 & 74 & 59 & 93 & 92 & 89 & 79 & 70 & 86 & 82 \\
\hline
\end{tabular}

${ }^{a}$ The number of trials completed prior to a run of 100 consecutive trials in which the percentage correct attained was at least $90 \%$.

${ }^{b}$ These animals were not tested on the $40 \mathrm{~min}$ delay for either DNMS-I or DNMS-Il.

mately $2.5 \mathrm{~mm}$ in transverse extent) was spared. The medial bank of the rhinal sulcus demonstrated an apparently intact layer II and III beginning at the rostral pole of the hippocampus and extending nearly to the caudal extent of the rhinal sulcus. $\mathrm{Nu}$ merous retrogradely labeled cells were observed in this region. The distal portions of the subicular complex were involved in the lesion, but the subiculum itself appeared to be intact. In addition the angular bundle was broached by the lesion, but only its medial portion was damaged. The lesion ended before the caudal pole of the entorhinal cortex leaving intact the most caudal extreme of the entorhinal cortex $(<1 \mathrm{~mm})$. The perirhinal and parahippocampal cortices were undamaged by the lesion on this side.

In summary, the lesion in animal E2 was relatively complete and selective for the entorhinal cortex. On the left side, there was no recognizable entorhinal tissue remaining, whereas on the right side, approximately $11.5 \mathrm{~mm}^{2}$ of the caudal entorhinal cortex was spared. This total is approximately $9 \%$ of the average entorhinal cortical area of the histological control animals. The lesion was therefore approximately $91 \%$ complete. The only significant bilateral extra-entorhinal damage was to the pre- and parasubiculum and to the angular bundle.

Monkey E3. The interpretation of the lesion damage in animal E3 was slightly complicated by the fact that some damage occurred to the ventromedial left hemisphere during extraction of the brain. This damage was mainly confined to the periamygdaloid cortex and ventromedial amygdala for a rostrocaudal distance of about $4 \mathrm{~mm}$. This animal clearly had more sparing of the entorhinal cortex bilaterally than animals E1 and E2. The rhinal sulcus was visible throughout most of its normal rostrocaudal extent bilaterally.

In the left hemispherc, the lesion began at the most rostral extreme of the entorhinal cortex, where most of layers II and III was removed in the medial two-thirds of the entorhinal cortex. The entorhinal cortex lining the medial bank of the rhinal sulcus and the lateral third of the cortex was largely intact, however, from the rostral pole of the entorhinal cortex and caudally for a distance of about $3.6 \mathrm{~mm}$. Retrogradely labeled neurons were present in layers II and III throughout this portion of spared entorhinal cortex. Beginning at approximately the midrostrocaudal level of the amygdala and extending to the genu of the hippocampus, all layers of the entorhinal cortex were ablated throughout the full transverse extent of the cortex. The lesion also damaged the angular bundle in this rcgion. Caudal to this level, the lesion gradually receded, both laterally and medially, sparing the entorhinal cortex that bordered the parasubiculum medially and areas 36 and TF laterally. The most caudal $1 \mathrm{~mm}$ of entorhinal cortex in the left hemisphere appeared largely spared by the lesion. In this region the angular bundle was largely intact. Other than the damage to the entorhinal cortex, there was only a small patch $(\approx 1.8 \mathrm{~mm}$ in rostrocaudal extent) of damage to medial area 36 at the level of the caudal amygdala. There was also a small region of superficial cortical thinning in rostral area 36 that extended into area TE. Unlike animals E1 and E2, monkey E3 sustained almost no damage to the subicular complex on either side. There was a short distance $(\approx 1.2 \mathrm{~mm})$ of damage to the parasubiculum.

The lesion in the right hemisphere of animal E3 was less extensive than in the left. Again, the lesion began at the most rostral extreme of the entorhinal cortex but only the midtransverse region of the entorhinal cortex was ablated. Thus, both medially and laterally situated entorhinal cortex was spared throughout the entire rostrocaudal extent of the entorhinal cortex. The caudal $1.2 \mathrm{~mm}$ of entorhinal cortex appeared to be intact. The medial portion of the angular bundle was involved in the lesion. The only extra-entorhinal damage sustained in the right hemisphere was a focal infarct in the lateral part of area 36 at the level of the amygdala.

In summary, the lesion in case E.3 was selective but less complete than in animals E1 and E2. On the left side, there was 
Table 2. Individual performance on tasks sensitive to amnesia

\begin{tabular}{|c|c|c|c|c|c|c|c|}
\hline \multirow[b]{2}{*}{ Group } & \multicolumn{5}{|c|}{$\begin{array}{l}\text { Delayed retention of object } \\
\text { discrimination } \\
\text { (\% correct })\end{array}$} & \multicolumn{2}{|c|}{$\begin{array}{l}\text { Concurrent object } \\
\text { discrimination } \\
\text { (trials to criterion) }\end{array}$} \\
\hline & $\begin{array}{l}\text { Day } \\
1\end{array}$ & $\begin{array}{l}\text { Day } \\
2 \\
\end{array}$ & $\begin{array}{l}\text { Day } \\
4 \\
\end{array}$ & $\begin{array}{l}\text { Mean } \\
\text { of } \\
3 \text { days } \\
\end{array}$ & Retest $^{a}$ & $\begin{array}{l}\text { st } \\
\text { test }\end{array}$ & Retest \\
\hline \multicolumn{8}{|l|}{ Normal } \\
\hline 1 & 77 & 95 & 93 & 88.3 & 83 & 240 & 120 \\
\hline 2 & 75 & 93 & 95 & 87.7 & 83 & 720 & 40 \\
\hline 3 & 71 & 90 & 93 & 84.7 & 76 & 640 & 40 \\
\hline 4 & 75 & 90 & 92 & 85.7 & 87 & 240 & 160 \\
\hline $5^{b}$ & 75 & 86 & 93 & 84.7 & - & 360 & - \\
\hline $6^{b}$ & 77 & 88 & 93 & 86.0 & - & 480 & - \\
\hline $7^{b}$ & 76 & 90 & 95 & 87.0 & - & 600 & - \\
\hline Mean & 75.1 & 90.3 & 93.4 & 86.3 & 82.2 & 468.6 & 90.0 \\
\hline \multicolumn{8}{|l|}{ Entorhinal } \\
\hline 1 & 69 & 91 & 96 & 85.3 & 99 & 400 & 69 \\
\hline 2 & 75 & 79 & 91 & 81.7 & 90 & 1137 & 172 \\
\hline 3 & 71 & 93 & 91 & 85.0 & 91 & 520 & 240 \\
\hline $4^{c}$ & 71 & 91 & 98 & 86.7 & - & 160 & 120 \\
\hline $5^{d}$ & 59 & 92 & 99 & 83.3 & 99 & 560 & - \\
\hline Mean & 69.0 & 89.0 & 95.0 & 84.4 & 94.7 & 555.4 & 150.2 \\
\hline
\end{tabular}

a Percentage correct calculated over one session of 20 trials.

${ }^{b}$ Did not receive the retests of object discrimination or concurrent object discrimination.

c Did not complete three of the four problems due to motivational problems.

${ }^{d}$ Did not receive the retest of concurrent object discrimination.

approximately $17.9 \mathrm{~mm}^{2}$ of spared entorhinal tissue, and on the right side there was $34.0 \mathrm{~mm}^{2}$ of spared cortex. Taken together, this total of $51.9 \mathrm{~mm}^{2}$ was approximately $39 \%$ of the average area of the entorhinal cortex of the histological control animals, i.e., the lesion removed approximately $61 \%$ of the entorhinal cortex.

Monkey E4. The lesion in case E4 was very similar to that in case E3. As with animal E3, the lesion was slightly more extensive in the left hemisphere, and in both hemispheres the lesion involved primarily the midtransverse portion of entorhinal cortex. In both hemispheres, there was spared tissue medially and laterally throughout most of the rostrocaudal extent of entorhinal cortex. Retrogradely labeled cells were observed in this spared tissue. The medial part of the angular bundle was ablated bilaterally through the length of the entorhinal cortex. There was no extra-entorhinal damage in either hemisphere in this animal.

In summary, the lesion in case E4 was selective for the entorhinal cortex but, as with case E3, substantial portions of the entorhinal cortex were spared bilaterally. On the left side, approximately $5.6 \mathrm{~mm}^{2}$ of spared entorhinal tissue was present and on the right side there was $22.5 \mathrm{~mm}^{2}$ of spared tissue. This total of $30.1 \mathrm{~mm}^{2}$ of entorhinal cortex accounted for approximately $23 \%$ of the average area of the entorhinal cortex of the histological control animals, i.e., the lesion removed approximately $78 \%$ of the entorhinal cortex.

Monkey E5. The lesion of monkey E5 was the most complete and selective of the $\mathrm{E}$ group. A series of photomicrographs through the rostrocaudal extent of this lesion is illustrated in Figure 4. The rhinal sulcus, or a portion of it, was visible throughout most of its normal rostrocaudal extent. There was little or no damage to the perirhinal or parahippocampal cortex in either hemisphere.
The lesion began in the left hemisphere at the rostral pole of the entorhinal cortex and also involved the most ventral part of the periamygdaloid cortex. There was minor intrusion by the lesion into the ventromedial amygdala for a short rostrocaudal distance. Except for a small patch of entorhinal cortex that was spared at its caudal pole, the remainder of the entorhinal cortex was entirely eliminated by the lesion. Although the medial bank of the rhinal sulcus was typically visible at all rostrocaudal levels of the entorhinal cortex (Figs. 2, 4), there were few, if any, layer II and III neurons in this region. In this case, the FB injection involved the uncal portion of the dentate gyrus and the underlying presubiculum. The DY injection was unfortunately misplaced within the medial portion of area TF of the parahippocampal cortex. Our analysis of the FB-labeled cells indicated that there were only a very few retrogradely labeled cells in the region of the rhinal sulcus. The entire angular bundle was eliminated on the left side. Thus, even if there were spared neurons on the medial bank of the rhinal sulcus, their connections with the remainder of the hippocampal formation would likely have been transected. At caudal levels of the entorhinal cortex, the lesion extended dorsomedially into the pre- and parasubiculum The subiculum itself, however, was intact. Other than the minor damage to the amygdala, the only extra-entorhinal damage involved the superficial layers of area TH for a short distance.

The lesion of the right hemisphere began at the same level as in the left hemisphere and slightly involved the periamygdaloid cortex and the amygdala. The remainder of the lesion on the right side was similar to that on the left. As on the left side, the lesion slightly involved the distal parts of the pre- and parasubiculum at caudal levels of the entorhinal cortex. The lesion involved slightly more of area $\mathrm{TH}(\approx 1.8 \mathrm{~mm})$ than on the left side.

In summary, the lesion in case E5 was the most selective and complete ablation of the entorhinal group. All layers of medially situated entorhinal cortex were completely ablated in both hemispheres. Of the small amount of laterally situated entorhinal cortex that occupied the medial bank of the rhinal sulcus, only the deep cell layers were recognizable. Extra-entorhinal cortical damage was negligible, and the damage to the subicular complex involved mainly the pre- and parasubiculum. Residual entorhinal cortex on the left side was approximately $2.3 \mathrm{~mm}^{2}$, and on the right side was $2.0 \mathrm{~mm}^{2}$. This total of $4.3 \mathrm{~mm}^{2}$ of entorhinal cortex is approximately $3 \%$ of the average area of the entorhinal cortex of the histological control animals, and thus the lesion removed approximately $97 \%$ of the entorhinal cortex in this case.

\section{Behavioral findings}

Tables 1 and 2 show the performance scores for individual monkeys on the three tasks shown previously to be impaired by medial temporal lobe lesions (Zola-Morgan and Squire, 1984, 1985): delayed nonmatching to sample (DNMS), delayed retention of object discriminations, and cight-pair concurrent object discrimination.

1. DNMS-I and DNMS-II. The delayed nonmatching-to-sample task was given to all monkeys on two different occasions. The interval between the first (DNMS-I) and second (DNMSII) administrations was 6-13 months for the E group and 6-9 months for the $\mathrm{N}$ group.

Basic task ( 8 sec). Figure $5, A$ and $C$, shows the mean number of trials required to achieve the $90 \%$ correct learning criterion when a delay of $8 \mathrm{sec}$ was interposed between the sample and choice. On DNMS-I (Fig. 5A), the E group required more trials 

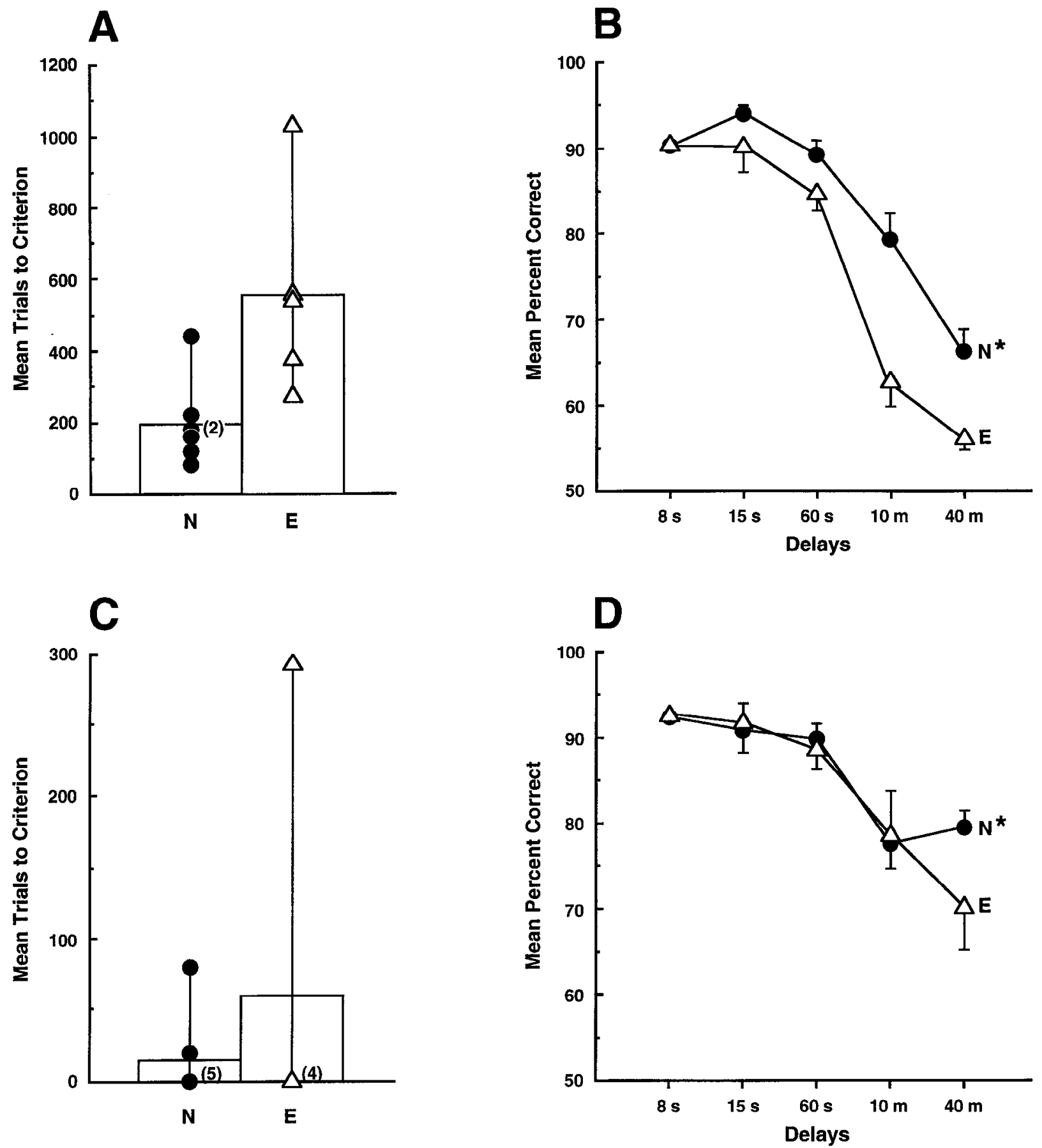

Figure 5. Performance on delayed nonmatching to sample (DNMS) for normal control monkeys $(N)$ and monkeys with bilateral lesions of the entorhinal cortex $(E)$. A, Learning of the task with a delay of $8 \mathrm{sec}$ on the first test occasion (DNMS-I). Symbols show scores for individual monkeys, and numbers beside symbols indicate the number of animals with the identical score (see Table 1). $B$, Performance across delays for the same groups on DNMS-I. $C$, Relearning of the task with a delay of $8 \mathrm{sec}$ at the second test occasion (DNMS-II). $D$, Performance across delays for the same groups on DNMS-II. All animals were tested with retention intervals of $15 \mathrm{sec}, 60 \mathrm{sec}$, and 10 min. The E group and four monkeys of the $\mathrm{N}$ group ( $\mathrm{N} 1-\mathrm{N} 4$, indicated by an asterisk) were additionally tested with a retention interval of 40 min. Error bars in $B$ and $D$ indicate standard error of the mean.

to reach criterion than the $\mathrm{N}$ group [557 trials vs 197 trials, respectively; $t(10)=3.0 ; p<0.05$ ]. In contrast, for DNMS-II (Fig. $5 C$ ) the $\mathrm{E}$ group and $\mathrm{N}$ group required a similar number of trials to regain criterion performance $(p>0.1)$. The majority of monkeys in both groups achieved learning criterion in the minimum number of trials (see Table 1).

Delays $(15 \mathrm{sec}, 60 \mathrm{sec}, 10 \mathrm{~min}, 40 \mathrm{~min}$ ). Because only four of seven animals in the $\mathrm{N}$ group were tested at the $40 \mathrm{~min}$ delay, scores from the $15 \mathrm{sec}, 60 \mathrm{sec}$, and 10 min delays were analyzed separately from the $40 \mathrm{~min}$ delay scores. Figure $5, B$ and $D$, shows the mean percentage correct scores across all delays for DNMS-I and DNMS-II, respectively.

For DNMS-I, a two-way repeated measures ANOVA (two groups and $15 \mathrm{sec}, 60 \mathrm{sec}, 10 \mathrm{~min}$ delays) revealed a significant effect of group $[F(1,10)=11.8, p<0.01]$, delay $[F(2,20)=$ $50.2, p<0.0001]$, and group $\times$ delay interaction $[F(2,20)=$ 


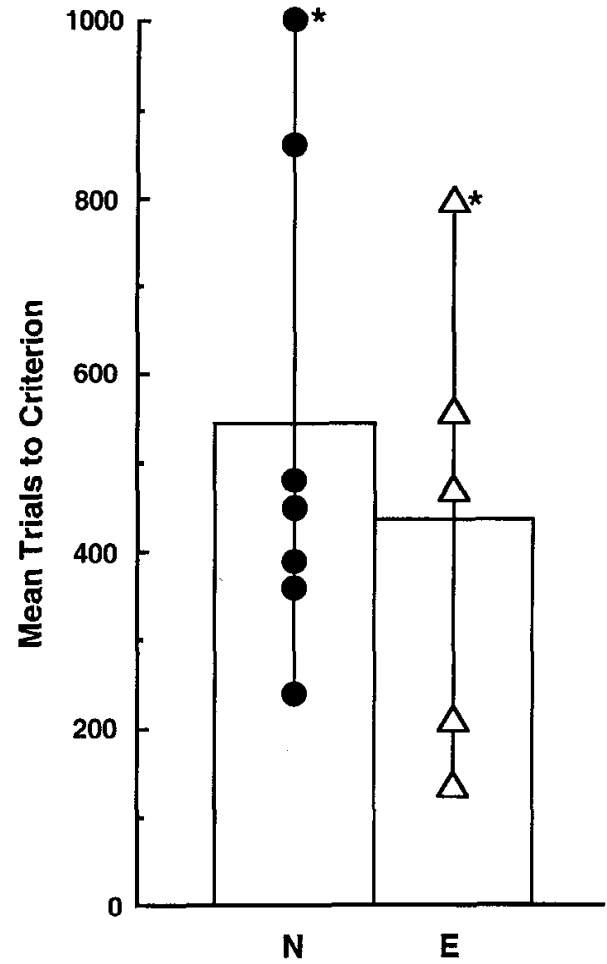

Figure 6. Mean scores for two pattern discrimination problems for normal control monkeys $(N)$ and monkeys with bilateral lesions of the entorhinal cortex $(E)$. Symbols show scores for individual monkeys. Asterisks indicate animals who did not reach criterion performance on one or both discrimination problems within 1000 trials.

$5.7, p<0.05]$. Separate comparisons for all four delay intervals (15 sec, $60 \mathrm{sec}, 10 \mathrm{~min}$, and $40 \mathrm{~min}$ delays) revealed that the $\mathrm{E}$ group was significantly impaired at the $10 \min (\mathrm{E}=63 \%$ vs $N$ $=79 \%)$ and $40 \mathrm{~min}(\mathrm{E}=56 \%$ vs $N=66 \%)$ delays $(p \mathrm{~s}<0.01)$ (Fig. $5 B$ ). The differences between groups at the $15 \mathrm{sec}$ and 60 sec delays were not significant ( $p s>0.1$ ). Although the E group performed at only $56 \%$ correct at the 40 min delay, this score was better than chance (i.e., $50 \%$ ) performance $[t(4)=4.6, p$ $=0.01]$.

On the second administration of DNMS, the E group was not impaired. A two-way repeated measures ANOVA (two groups, $15 \mathrm{sec}, 60 \mathrm{sec}, 10 \mathrm{~min}$ delays) revealed no differences between the $\mathrm{E}$ group and the $\mathrm{N}$ group (all $p s>0.1$ ). An effect of delay was detected $[F(2,20)=20.1, p<0.0001]$, indicating that, as on DNMS-I, overall performance declined for both groups as the delay increased from $15 \mathrm{sec}$ to $10 \mathrm{~min}$. Separate comparisons based on each group's scores at the $15 \mathrm{sec}, 60 \mathrm{sec}, 10 \mathrm{~min}$, and 40 min delays found no differences between the E group and $N$ group at any delay (all $p s>0.1$ ) (Fig. $5 D$ ). We should point out that animal E5 demonstrated aberrant performance on the second administration of DNMS (Table 1). The number of trials to criterion (294) was actually greater than on the first administration of the task. Detailed notes from the testing procedures indicates that this may have been due to motivational problems associated with housing changes in the colony. When the colony was restored to its original condition, performance of E5 returned to normal. Perhaps the most salient aspect of the data from this animal was that at the $10 \mathrm{~min}$ and $40 \mathrm{~min}$ delays (which were the only ones demonstrating an impairment in the first administration of DNMS) animal E5 showed an improvement similar to that of the other animals in the group.

We next addressed the question of how the relative performance of the $\mathrm{E}$ and $\mathrm{N}$ groups changed across the two testing occasions. The $15 \mathrm{sec}, 60 \mathrm{sec}$, and $10 \mathrm{~min}$ delay scores were averaged separately for DNMS-I and DNMS-II, producing two scores for each animal. A two-way repeated measures ANOVA (two groups, two test occasions) revealed a significant group $X$ test occasion interaction $[F(1,10)=8.1, p=0.02]$, indicating that the pattern of performance of the $E$ and $N$ groups differed across DNMS-I and DNMS-II. In addition, separate paired $t$ tests showed that the $\mathrm{E}$ group performed better on DNMS-II compared to DNMS-I $[t(4)=4.9, p<0.01]$, whilc the $\mathrm{N}$ group performed similarly on the two tests $[t(6)<1]$. For the E group, the same pattern of results was obtained when the $10 \mathrm{~min}$ and 40 min delay data were analyzed separately. Numerically, the E group exhibited an average improvement of $16 \%$ at the $10 \mathrm{~min}$ delay $[t(4)=3.9, p<0.02]$, while the $\mathrm{N}$ group exhibited an average decrement of $-2.0 \%[t(6)<1]$. At the $40 \mathrm{~min}$ delay, the E group also improved their performance $[t(4)-3.4, p<$ $0.03 \mathrm{j}$. Unexpectedly, the four animals in the $\mathrm{N}$ group that received the $40 \mathrm{~min}$ delay also improved their performance $[t(3)$ $=3.6, p<0.04]$. However, as stated above, this stands in contrast to the lack of a detectable improvement by the normal animals at the other three delays (overall average $=-2.0 \%$ ).

2. Pattern discrimination. Two tests of pattern discrimination were administered sequentially ( $\square$ vs + and $N$ vs W). The number of trials needed to reach the $90 \%$ correct learning criterion was avcraged for the two problems, producing a single score for each animal (Fig. 6). One entorhinal animal (E2) and one normal animal (N3) did not reach criterion after 1000 trials, on one of the problems and they were assigned scores of 1000 trials for that problem. On the other problem, monkey E2 and N3 attained criterion in 591 trials and 720 trials, respectively. Overall, they were assigned an average score of 796 and 860 trials, respectively. Monkey N1 performed continually at chance levels on both problems, and testing was discontinued after 1000 trials. This monkey was assigned an average score of 1000 trials. (Monkey N1 and N3 were referred to as N4 and N6 in ZolaMorgan, et al., 1989b.)

As with other medial temporal lobe lesion groups, pattern discrimination learning was unimpaired by entorhinal lesions. The $\mathrm{E}$ group and $\mathrm{N}$ group required a similar number of trials to reach learning criterion (433 trials vs 540 trials, respectively; $p$ $>0.1$ ).

Delayed retention of object discriminations. Figure 7 shows the performance of the $\mathrm{E}$ group and $\mathrm{N}$ group on the object discrimination task for the $2 \mathrm{~d}$ of training (i.e., day 1 and day 2), the $48 \mathrm{hr}$ retention test (i.e., day 4 ), and the retest carried out approximately 6 months later. The daily percentage correct scores were averaged across the four discrimination problems to yield four scores for each animal. On the first day of testing, the E group obtained numerically lower scores than the $\mathrm{N}$ group (69.0 vs $75.1 \%$ ), but this difference was not significant $(p>$ 0.10 ). A two-way repeated measures ANOVA (two groups, day 1 , day 2 , day 4) revealed only a significant effect of days $[F(2,20)=92.6, p<0.0001]$, indicating that, overall, performance improved across days (group and group $\times$ day interaction $p s>0.08$ ). The $\mathrm{E}$ animals and the $\mathrm{N}$ animals performed at similar levels overall, averaging $84 \%$ correct and $86 \%$ correct, respectively, over the $3 \mathrm{~d}$ of testing ( $p>0.05$ ).

Retest of object discrimination. All of the $\mathrm{E}$ group animals 


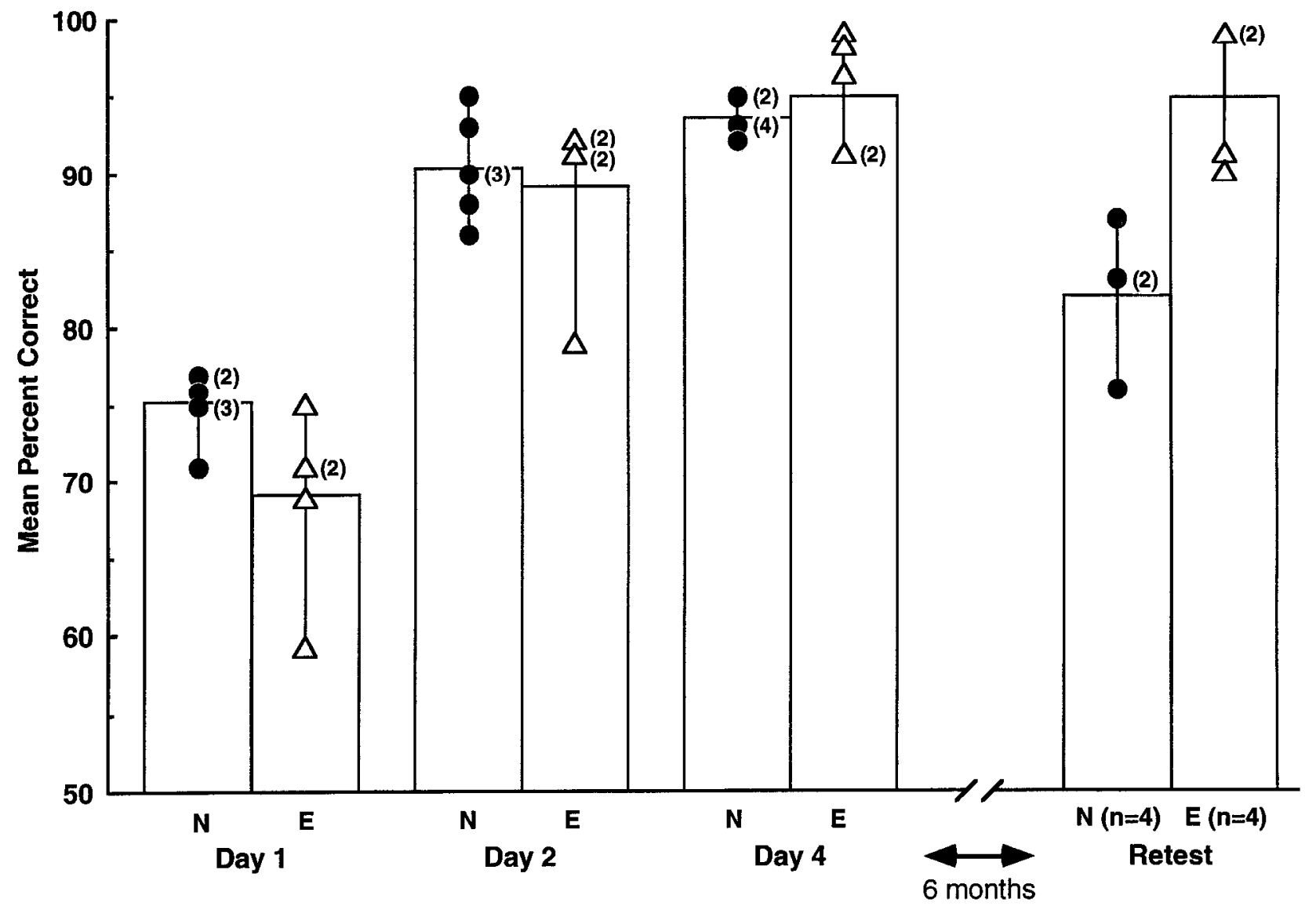

Figure 7. Average daily and retest performance on four object discrimination problems for normal control monkeys $(N)$ and monkeys with bilateral lesions of the entorhinal cortex $(E)$. The $\mathrm{E}$ monkeys and four monkeys of the $\mathrm{N}$ group (N1-N4) received a retest of the discrimination problems 6-10 months after learning. One monkey of the E group (E4) was excluded from the retest analysis because of motivational problems. Symbols show scores for individual monkeys. Numhers heside symbols indicate the number of monkeys that attained the same average score.

and four of the normal control animals (N1-N4) received a retest of each object discrimination pair during the 1-month retention interval of the lifesaver motor skill task (see below). The average interval between the two administrations of the object discrimination task was 7 months for the $\mathrm{E}$ group (range, 6-10 months) and about 6 months for the $\mathrm{N}$ group (range, 5-6 months). One object pair was given per day for a total of 20 trials. The percentage correct scores were averaged across the four discrimination problems to yield one score for each animal. One entorhinal animal (E4) completed 20 trials on the first object pair, but only 11 trials on the second pair due to motivational problems. Testing was discontinued on the remaining object pairs, and this animal was excluded from the analysis of the retest data. Figure 7 shows the retest scores. The E group performed better than the $\mathrm{N}$ group at the retest [95\% correct vs $82 \%$ correct, respectively; $t(6)=3.7, p<0.01]$. Separate within-group comparisons also indicated no forgetting in the E group $(n=4)$ during the 6-month retention interval (94\% correct on day 4 vs $95 \%$ correct on retest), while the $\mathrm{N}$ group $(n=4)$ exhibited significant forgetting [ $93 \%$ correct on day 4 vs $82 \%$; paired $t(3)$ $=4.4, p=0.02]$.

A potentially more sensitive measure of forgetting across the two administrations of the object discrimination task is the probability of a correct response on the very first trial of the retest. For this analysis, the number of correct and incorrect choices on the first trial of each of the four discrimination problems was tallied for each animal, both for the first administration and for the retest. As expected, both experimental and control groups scored near chance on the first trial of the first administration of the task (separate one-group chi-square tests; $p s>0.05$ ). On the second administration, both the $\mathrm{E}$ and $\mathrm{N}$ groups displayed evidence of long-term object-pair retention. The $\mathrm{E}$ group $(n=$ 4) had a total of 15 correct and 1 incorrect choices $\left[\chi^{2}(1)=\right.$ 11.6, $p<0.001]$, while the $\mathrm{N}$ group $(n=4)$ had a total of 11 correct and 3 incorrect choices (two normal animals did not receive the retest for one of the four discrimination problems, thus only 14 first choices were available for this analysis) $\left[\chi^{2}(1)\right.$ $=4.6, p<0.05]$.

Concurrent object discrimination. Figure 8 shows the performance on the eight-pair concurrent object discrimination task for the first administration and the retest. The mean number of trials to reach the learning criterion ( 39 correct choices out of 40) was similar for the control animals and the animals in the E group $(p>0.1)$. The E group took an avcragc of 555 trials to reach the criterion, and the $\mathrm{N}$ group took an average of 469 trials.

Retest of concurrent object discrimination. Four of the $\mathrm{E}$ group animals (E1-E4) and four normal control animals (N1N4) were retested on concurrent object discrimination. This retest occurred during the 1 -month retention interval of the lifesaver motor skill task (see below). The average interval between the two administrations was 6 months (range, 5-7 months) for the $\mathrm{E}$ group and 4 months for the $\mathrm{N}$ group. The $\mathrm{E}$ group and $\mathrm{N}$ group required a similar number of trials to relearn the concur- 


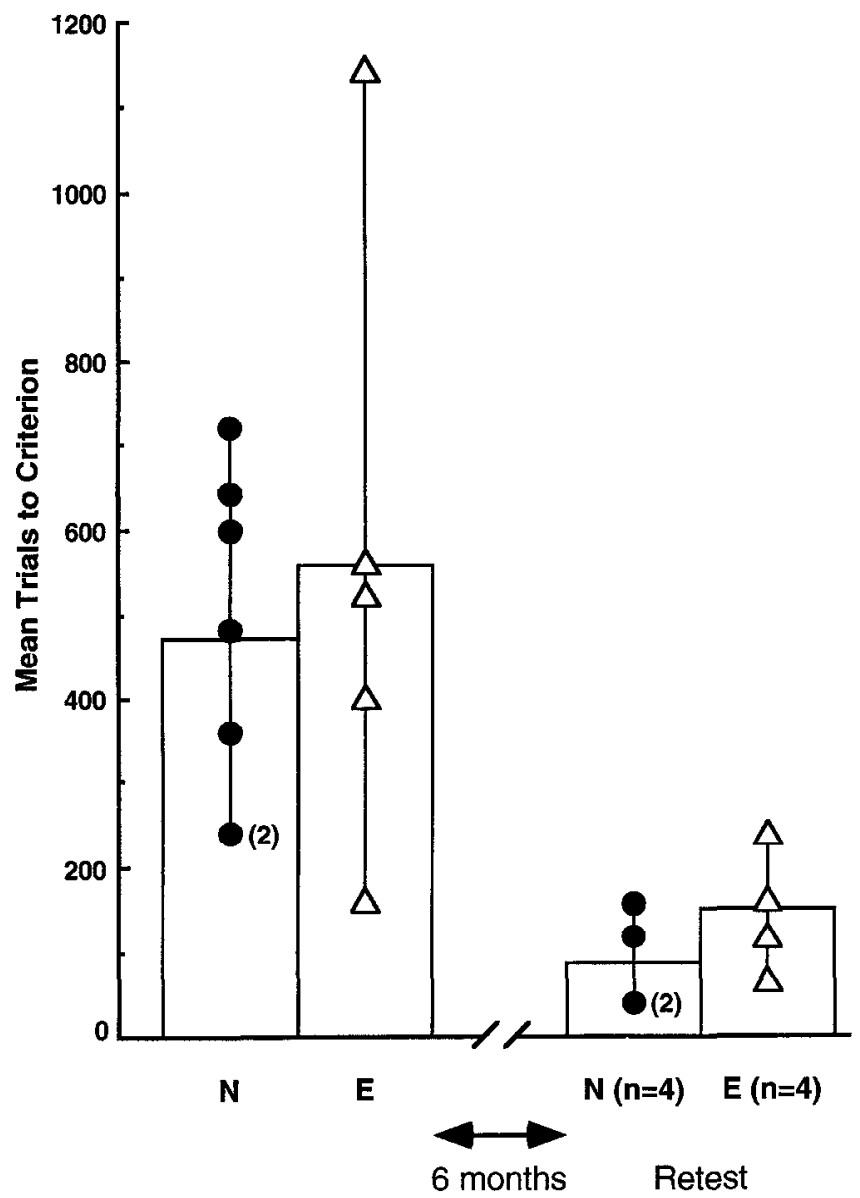

Figure 8. Average scores for the eight-pair concurrent object discrimination test and retest for normal control monkeys $(N)$ and monkeys with bilateral lesions of the entorhinal cortex $(E)$. Four monkeys of the $\mathrm{E}$ group (E1-E4) and four monkeys of the $\mathrm{N}$ group $(\mathrm{N} 1-\mathrm{N} 4)$ received the retest of the concurrent discrimination 4-7 months after learning. Symbols show scores for individual monkeys, and numbers beside symbols indicate the number of animals with the identical score.

rent object discrimination task (150 trials vs 90 trials, respectively; $p>0.1$ ).

Lifesaver motor skill. Four E monkeys (E1-E4) and four $\mathrm{N}$ animals (N1-N4) were trained and then retested on this task in which monkeys obtain a candy lifesaver by removing it from an angled metal rod. The lifesaver task was administered daily for $8 \mathrm{~d}$, followed by a 1-month retention interval, and then a performance test for two daily sessions. Six timed trials per day were given, and the average daily solution time was calculated separately for each animal. The data from one entorhinal animal (E3) was excluded because of apparent motivational problems. Although this monkey usually made an attempt on each trial, he often gave up after just a few seconds. The E group's performance was indistinguishable from the $\mathrm{N}$ group's performance. A two-way repeated measures ANOVA (two groups, $8 \mathrm{~d}$ of training) revealed only a significant effect of training $[F(7,35)$
$=16.4, p<0.0001]$, indicating that, overall, solution time became faster across the $8 \mathrm{~d}$ of training (group and group $\times$ day interaction, $p s>0.1$ ). The average retrieval time on the first day of training was $22.2 \mathrm{sec}$ and $24.8 \mathrm{sec}$, respectively for the $\mathrm{N}(n=4)$ and $\mathrm{E}(n=3)$ groups, and $5.0 \mathrm{sec}$ and $8.3 \mathrm{sec}$ on the eighth day of training. A similar analysis of the retest data produced the same pattern of results ( $\mathrm{N}$ group, $5.5 \mathrm{sec}$; $\mathrm{E}$ group, $4.4 \mathrm{sec})$.

\section{Neuroanatomical findings}

Retrograde tracers. All five $\mathrm{E}$ animals had at least one retrograde tracer successfully deposited into the hippocampal formation. The majority of the Fast blue (FB) and diamidino yellow (DY) dye deposits were restricted to the CA1 region and dentate gyrus of the midbody of the hippocampal formation. The cores of the CAl dye injections were typically restricted either to the distal part of the field or also involved the proximal portion of the subiculum. The cores of the dye deposits in the dentate gyrus were typically restricted to the molecular layer but sometimes also involved the granule cell layer and cells of the hilus. Figure 9 illustrates the distributions of FB- and DY-labeled neurons through selected levels of the medial temporal lobe of two animals (E1 and E4) in the $\mathrm{E}$ group. The goals of these tracer experiments were threefold: (1) to aid in identifying spared entorhinal cortex (as described earlier); (2) to determine whether perirhinal projections to the hippocampal formation were intact and (3) to determine which other cortical areas were projecting to the hippocampal formation following the entorhinal lesions.

Monkey E1 (left side, Fig. 9) had very few retrogradely labeled cells in the ventrally situated perirhinal cortex, although there were a few labeled cells in the temporal polar portion of area 36 . The number of labeled cells throughout the perirhinal region, however, was much reduced relative to expected levels (ct. Suzuki and Amaral, 1990). In contrast, monkey E4 had robust retrograde labeling in area 36 . This difference in perirhinal labeling can most likely be explained by the fact that the angular bundle was largely intact in monkey E4 and nearly completely transected in monkey E1. There were a substantial number of neurons labeled in areas TF and $\mathrm{TH}$ in both animals. In addition to the parahippocampal labeling, relatively small numbers of retrogradely labeled cells were observed in caudal area 13 of the frontal lobe, in areas 32, 24, 23, and 29 of the cingulate cortex, the peri-insular cortex, and along the dorsal bank of the superior temporal gyrus. The expected (Amaral and Cowan, 1980) variety of subcortical structures also demonstrated retrogradely labeled cells including the claustrum, amygdala, medial septal nucleus, and nucleus of the diagonal band, lateral hypothalamus, and supramamillary region, ventral tegmental area, nucleus reuniens of the thalamus, raphe nuclei, and locus coeruleus.

Measurements of the dentate molecular layer and stratum lacunosum-moleculare of CAI. The cross-sectional area of the molecular layer of the dentate gyrus was measured at five standard levels in the $\mathrm{E}$ group and the histological control group (see Lesion evaluation section in Materials and Methods). There appeared to be an average $25 \%$ decrease in the area of the dentate

Figure 9. Computer generated plots of the distribution of retrogradely labeled neurons in representative sections of the left temporal lobes of entorhinal-lesioned monkeys E1 and E4. Plots are arranged from rostral (top) to caudal (bottom) for each animal. Each dot represents one labeled neuron. Deposits of Fast blue and diamidino yellow are displayed as shaded ovals, approximating the extent of dye diffusion. Open arrowheads bracket the extent of the lesion, and filled arrowheads indicate cytoarchitectonic boundaries. Additional abbreviations: $a b$, angular bundlc; $S$, subiculum. Scale bar, $1 \mathrm{~mm}$. 

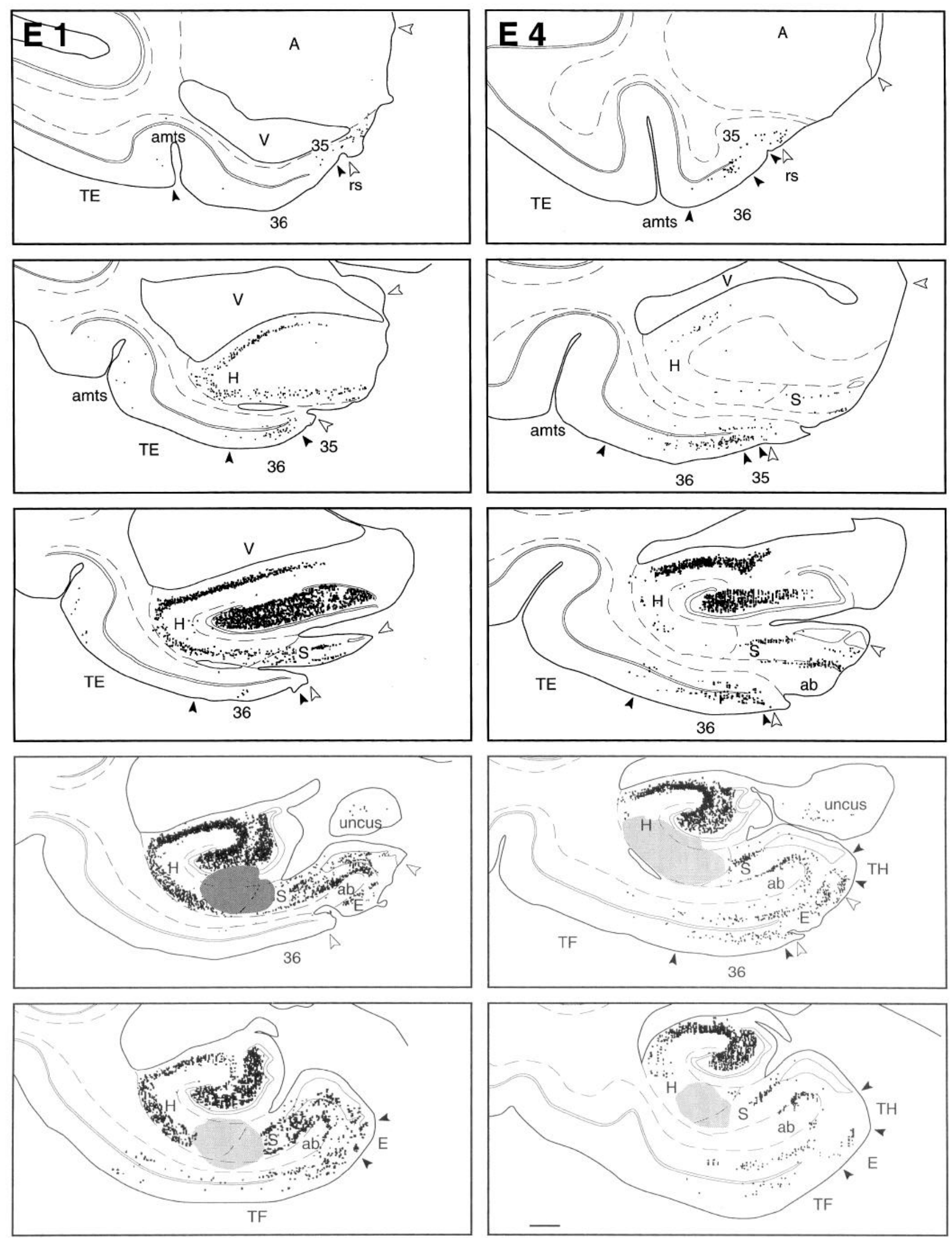
Table 3. Quantitative data on stratum lacunosum-moleculare (sIm) and perirhinal-hippocampal (PR) projection in anatomical control monkeys and entorhinal-lesioned monkeys

\begin{tabular}{|c|c|c|c|c|c|c|c|c|c|c|c|c|c|c|}
\hline \multirow[b]{2}{*}{$\begin{array}{l}\text { Group } \\
\text { animal }\end{array}$} & \multirow{2}{*}{$\begin{array}{l}\text { slm width/ } \\
\text { (slm }+ \text { sr) } \\
\text { width }^{a}\end{array}$} & \multicolumn{6}{|c|}{ slm length $(\mathrm{mm})^{h}$} & \multicolumn{6}{|c|}{ Perirhinal terminal field length $(\mathrm{mm}) \mathrm{c}$} & \multirow{2}{*}{$\begin{array}{l}\text { Mean PR field } \\
\text { length/Mean } \\
\text { slm length }\end{array}$} \\
\hline & & $\begin{array}{l}\text { Level } \\
1 \\
\end{array}$ & $\begin{array}{l}\text { Level } \\
2\end{array}$ & $\begin{array}{l}\text { Level } \\
3 \\
\end{array}$ & $\begin{array}{l}\text { Level } \\
4\end{array}$ & $\begin{array}{l}\text { Level } \\
5 \\
\end{array}$ & Mean & $\begin{array}{l}\text { Level } \\
1 \\
\end{array}$ & $\begin{array}{l}\text { Level } \\
2\end{array}$ & $\begin{array}{l}\text { Level } \\
3 \\
\end{array}$ & $\begin{array}{l}\text { Level } \\
4\end{array}$ & $\begin{array}{l}\text { Level } \\
5 \\
\end{array}$ & Mean & \\
\hline \multicolumn{15}{|l|}{ Control } \\
\hline M-1-88 & 0.550 & 3.36 & 3.49 & 3.51 & 2.10 & 2.64 & 3.02 & 2.24 & 2.10 & 2.15 & 1.82 & 1.64 & 1.99 & 0.659 \\
\hline M-7-91 & 0.558 & 3.14 & 3.13 & 3.21 & 3.02 & 2.68 & $\mathbf{3 . 0 3}$ & 1.58 & 1.89 & 1.96 & 1.78 & 2.00 & 1.84 & 0.607 \\
\hline M-12-91 & 0.586 & 2.71 & 2.71 & 3.14 & 3.41 & 3.06 & 3.01 & 1.42 & 1.43 & 1.70 & 1.91 & 1.73 & 1.64 & 0.545 \\
\hline Meaıı & 0.559 & $\mathbf{3 . 2 5}$ & 3.46 & 3.58 & 3.35 & 3.32 & 3.39 & 1.65 & 1.76 & 1.89 & 1.94 & 2.06 & 1.86 & 0.548 \\
\hline \multicolumn{15}{|l|}{ Entorhinale } \\
\hline 1 & 0.415 & 4.35 & 4.16 & 4.12 & 3.66 & 3.35 & 3.93 & 3.63 & 3.42 & 3.63 & 3.41 & 3.15 & 3.45 & 0.878 \\
\hline 4 & 0.464 & 3.04 & 3.52 & 3.64 & 3.55 & 3.26 & 3.40 & 1.84 & 1.81 & 1.98 & 2.11 & 1.75 & 1.90 & 0.571 \\
\hline 5 & 0.450 & 3.49 & 4.11 & 4.36 & 3.51 & 3.22 & 3.74 & 3.05 & 3.40 & 3.52 & 2.71 & 2.33 & 3.00 & 0.802 \\
\hline E-315 & 0.439 & 5.33 & 4.70 & 4.32 & 3.54 & 3.23 & 4.23 & 5.16 & 4.44 & 3.88 & 3.40 & 2.68 & 3.91 & 0.924 \\
\hline
\end{tabular}

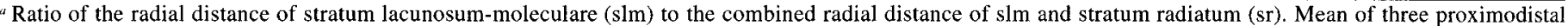
points in the CAl field.

${ }^{b}$ Transverse length of $\operatorname{sim}$ between $\mathrm{C} \wedge 2$ and subiculum measured at five standardized rostrocaudal levels.

: Transverse length of perirhinal-hippocampal terminal field between CA2 and subiculum measured at same five rostrocaudal levels.

${ }^{d}$ Ratio of the mean transverse length of the perirhinal-hippocampal terminal field to the mean length of slm.

${ }^{e} \mathrm{E}$ animals E2 and E3 were excluded from analyses (see Results). Animal E-315 had a complete entorhinal lesion, but was not used in the behavioral studies.

$* p<0.03$.

$* * p<0.01$.

NS, not significant at $p<0.05$.

molecular layer of the E group. This is consistent with the areal loss after entorhinal lesions in rats following long-term survival (Cotman and Lynch, 1976). The radial extent of the stratum lacunosum-moleculare of CA1 was also measured (Table 3). Stratum lacunosum-moleculare in the E group animals accounted for a smaller proportion of the radial extent of the combined distance of strata radiatum and lacunosum-moleculare than in the control group. This is in contrast to the transverse extent of stratum lacunosum-moleculare, which was similar in the control and $\mathrm{E}$ group animals. Thus, there was shrinkage in the radial dimension of the CAl field but not in the transverse dimension.

Anterograde tracers. As noted above, injections of ${ }^{3} \mathrm{H}$-amino acids were also placed into the perirhinal region in order to assess whether projections from the perirhinal cortex to the CA1/ subiculum border were intact. Three of the five isotope injections were restricted to the medial part of area $36(\mathrm{E} 1, \mathrm{E} 4, \mathrm{E} 5)$. The other two injections additionally involved the CA1 field of the hippocampus or the subiculum and were not analyzed further. The ${ }^{3} \mathrm{H}$-amino acid injection in the entorhinal-lesioned animal who was not part of the behavioral study (E-315) was also restricted to the medial part of area 36 and was subjected to neuroanatomical evaluation. These preparations were also studied to determine whether there was sprouting of the perirhinal-hippocampal connections. If there was substantial sprouting of these projections, it might provide one possible explanation for the behavioral recovery that was observed between the first and second testing sessions on DNMS.

Figure 10 illustrates one hypothesis. In the intact brain (Fig. $10 A$ ), there exists a direct ipsilateral projection from the perirhinal cortex to the border of the CA1 field with the subiculum. This projection extends for much of the rostrocaudal extent of the hippocampus (Suzuki and Amaral, 1990). This direct projection overlaps substantially with the perforant path termination within CA1 and the subiculum (see Witter and Amaral, 1991). As depicted in Figure $10 B$, entorhinal cortical ablation would lead to degeneration in the perforant path terminal fields in the dentate gyrus, hippocampus, and subiculum and would result in vacated synaptic space. The question of interest was whether intact perirhinal fibers that terminate close to these regions might sprout not only to incrcase their synaptic domain in CA1, the subiculum, and CA3, but also possibly to cross the hippocampal fissure and form a new projection to the molecular layer of the dentate gyrus. This latter projection would essentially reconstitute the "trisynaptic circuit" by bringing sensory information directly to the dentate gyrus that was originally relayed through the entorhinal cortex.

Although there was no evidence that a substantial new projection from the perirhinal cortex sprouted into the denervated molecular layer of the dentate gyrus, the distribution of silver grains in stratum-lacunosum moleculare of the CAl field in the E animals extended more proximally (toward CA3) than in the control animals (Fig. 11). These observations were confirmed in our quantitative analyses (Table 3). The average transverse extent of stratum lacunosum-moleculare was similar in the control and $E$ group animals (3.39 $\mathrm{mm}$ vs $3.82 \mathrm{~mm}$, respectively). However, the average transverse distance of the perirhinal terminal field in CA1 was nearly $70 \%$ greater in the E group than in the control group [3.07 mm vs $1.86 \mathrm{~mm}$, respectively; $t(7)=3.02$, $p<0.02$ ]. In summary, we found that the perirhinal projection to the hippocampus occupied a significantly wider terminal field in the $\mathrm{E}$ group animals than in the control animals. Thus, pyramidal cells in the proximal portion of CA1 that do not normally receive a direct perirhinal input may be innervated in the $\mathrm{E}$ group animals (assuming the fibers and terminals in the expanded zone actually contact C.A1 neurons). A complete trisynaptic circuit was not reconstituted, however, because there was 

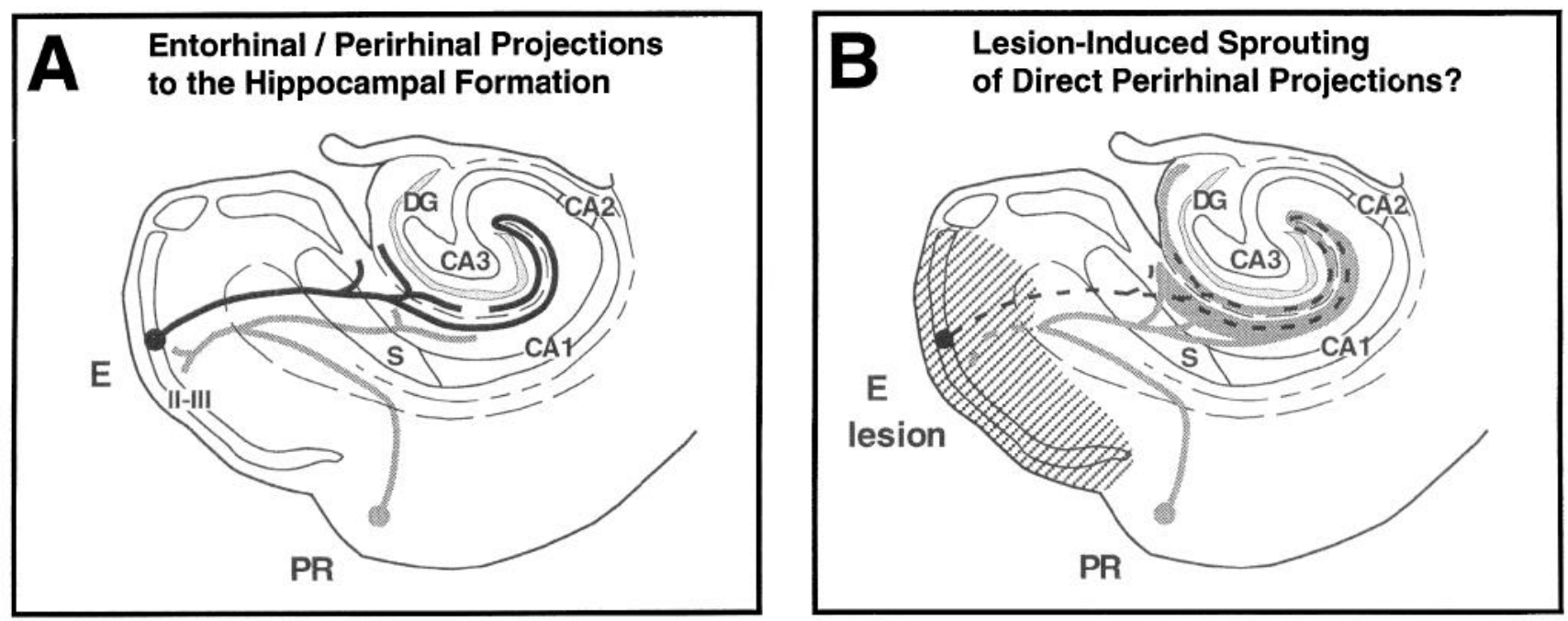

Figure 10. Schematic illustration of hypothetical lesion-induced sprouting of perirhinal connections into the hippocampus and dentate gyrus as a possible substrate for behavioral recovery of memory function of entorhinal-lesioned monkeys. $A$, In the intact brain, the hippocampus (CAI, $C A 2$, $C A 3)$ and subiculum $(S)$ receive direct projections from both entorhinal $(E)$ and perirhinal cortices $(P R)$, while the dentate gyrus receives direct projections only from the E. B. After ablation of the $\mathrm{E}$ (hatched region), degenerating axons (dashes) in the dentate gyrus and hippocampus would vacate synaptic space, possibly inducing novel and/or expanded terminal fields (gray shading) originating from cells in the perirhinal cortex.

clearly no formation of an aberrant projection to the dentate gyrus.

\section{Discussion}

The intent of the present study was to evaluate the role of the monkey hippocampal formation in memory functions. The main finding of the present study was that virtually complete bilateral ablation of the monkey entorhinal cortex produced only a mild impairment of memory function. Moreover, the impairment was transient. When animals were retested nearly 1 year after the original testing, they performed normally.

\section{Characterization of the behavioral impairment}

Of all the tasks administered, the E group was impaired only on the first administration of DNMS. During initial learning, the E group animals took, on average, three times as many trials as $\mathrm{N}$ animals to reach the same criterion level of performance (Table 1). On the delay portion of DNMS, the E group performed as well as the control group at $15 \mathrm{sec}$ and $60 \mathrm{sec}$ retention intervals. When the retention interval was increased to $10 \mathrm{~min}$ or $40 \mathrm{~min}$, however, the E group was significantly impaired.

\section{Is the memory deficit due to incomplete lesions?}

Although there was some variability in the size and location of the lesions, it is not likely that spared entorhinal tissue can account for the findings. The average surface area of residual entorhinal cortex in the $\mathrm{E}$ group was only $17 \%$; one animal had only $3 \%$ residual entorhinal cortex, and two others had approximately $10 \%$. Moreover, close examination of the Nissl-stained sections consistently showed disrupted cellular organization of the residual, unaspirated entorhinal cortex including a thinning of layer II and III.

\section{Is the memory deficit due to damage to structures other than the entorhinal cortex?}

Neuroanatomical analysis appears to rule out that the memory deficit could be due to inadvertent damage to the perirhinal or parahippocampal cortex. Perirhinal cortical damage was gener- ally unilateral, restricted to a small region, and uncorrelated with DNMS performance. The delay performance of animal E1, for example, who sustained the most perirhinal damage, was numerically similar to that of animal E5, who sustained no damage to the perirhinal cortex. One caveat to this conclusion is that the entorhinal cortex provides a major input to the perirhinal and parahippocampal cortices (Suzuki and Amaral, 1994a,b). If one supposes that the perirhinal and/or parahippocampal cortices are important for mediating the memory demands of the DNMS task, then elimination of the entorhinal projection to the perirhinal and parahippocampal cortices could have a disabling effect on the mnemonic function of these cortices, which is most evident when delays are extended to 10 and $40 \mathrm{~min}$. This possibility cannot be currently ruled out.

\section{Comparison with other lesion studies of the entorhinal cortex}

Our results confirm and extend the findings of Meunier et al. (1993), who also studied the effects of entorhinal lesions on visual recognition in rhesus monkeys. Their study differed in several ways, however, from the work reported here. First, the entorhinal lesions were all carried out in two stages, whereas our bilateral surgery was carried out in one stage. Second, their entorhinal lesions tended to be less complete than ours, sparing on average $25 \%$ of the surface area of the entorhinal cortex. Third, their lesions consistently included substantial damage to the perirhinal cortex. Fourth, training on DNMS was carried out preoperatively, whereas our behavioral testing was all done postoperatively. Fifth, the longest delay for DNMS was $2 \mathrm{~min}$, whereas we tested $10 \mathrm{~min}$ and $40 \mathrm{~min}$ delays. Finally, in their procedure, the task was made more difficult by increasing list length to 10 items. Despite these differences, Meunier et al. (1993) concluded that damage to the entorhinal cortex alone produced only a mild deficit on DNMS. Their entorhinal group, for example, was not different from control animals on relearning the task postoperatively at the $10 \mathrm{sec}$ delay. Moreover, although their entorhinal animals were impaired overall on the delay conditions, on the list length tests, their performance was not different from the normal control animals. The results of the 

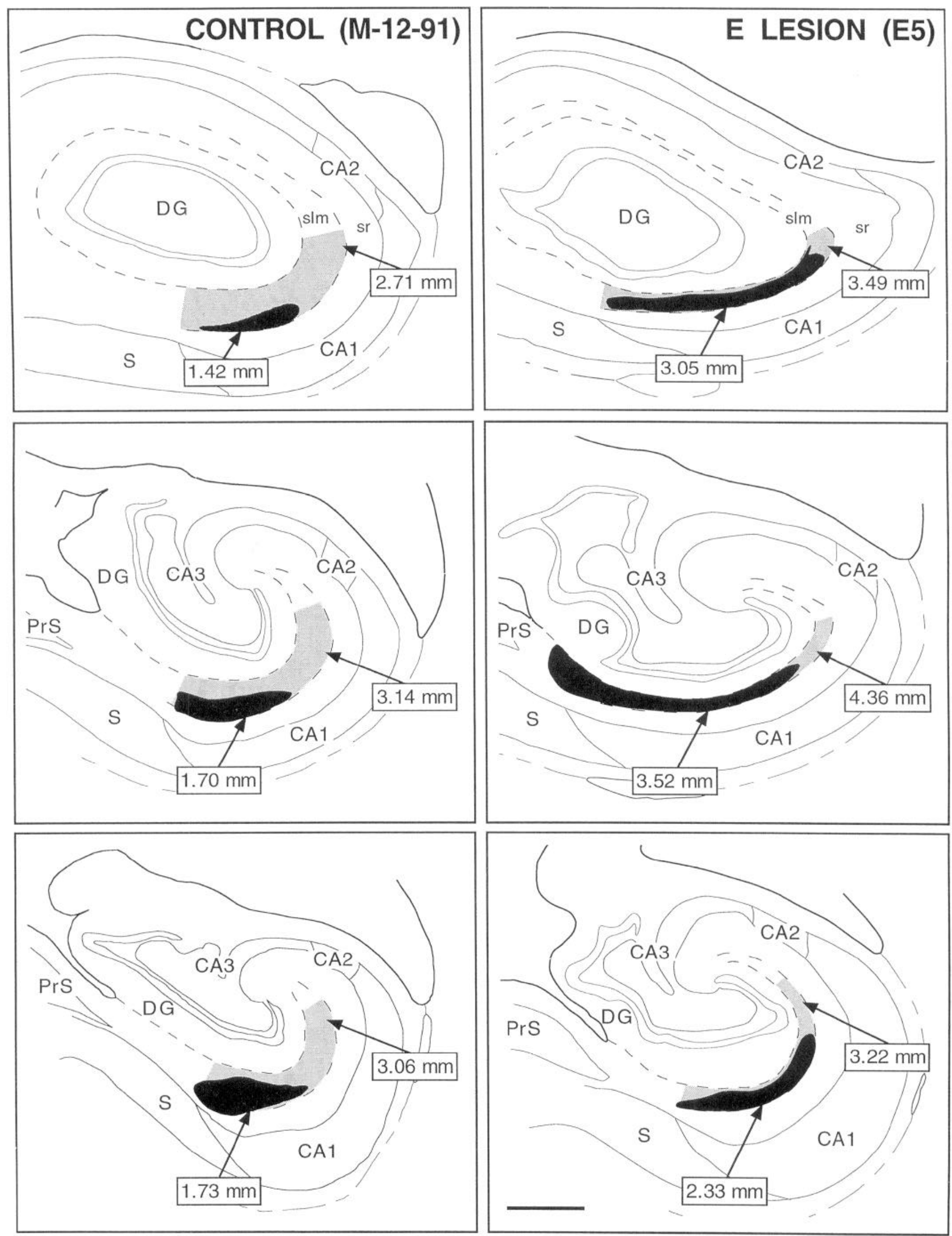
present study indicate that neither the two-stage lesion, nor the sparing of entorhinal tissue in the Meunier et al. (1993) study is likely to be responsible for the mild DNMS deficit they observed. In the one stage, more extensive lesions of the current study produced similar results.

\section{Comparison with other medial temporal lobe lesions}

The effects of selective entorhinal lesions can be placed in the context of earlier lesion studies in which other medial temporal lobe regions were damaged and the behavioral impairment was much more severe. For example, bilateral ablation of the hip pocampal formation, amygdaloid complex, and surrounding neocortex (the $\mathrm{H}^{+} \mathrm{A}^{+}$lesion) produces a severe and enduring memory impairment (Mishkin, 1978; Murray and Mishkin, 1984; Zola-Morgan and Squire, 1985). Although the initial interpretation of these data was that the hippocampal formation and amygdala were independently involved in visual recognition memory (Mishkin, 1978), emphasis has now shifted to the hippocampal formation and the adjoining cortical regions, i.e., the perirhinal and parahippocampal cortices, which were also damaged in the $\mathrm{H}^{+} \mathrm{A}^{+}$lesion (Mishkin and Murray, 1994; Zola-Morgan and Squire, 1993).

This reassessment was prompted by several findings. Lesions limited to the perirhinal and parahippocampal cortices (the PRPH lesion) and combined lesions of the hippocampal formation, parahippocampal cortex, and perirhinal cortex (the $\mathrm{H}^{++}$ lesion) impaired memory on DNMS nearly as much as the $\mathrm{H}^{+} \mathrm{A}^{+}$ lesion (Zola-Morgan et al., 1989, 1993; Suzuki, et al., 1993). In addition, circumscribed amygdala lesions did not affect memory (Zola-Morgan et al., 1989a). Finally, perirhinal lesions produced a more substantial impairment of DNMS than lesions in any other single region of the medial temporal lobe (Meunier et al., 1993; Mishkin and Murray, 1994). When this perirhinal lesion was combined with the entorhinal lesion, the resulting impairment on DNMS was almost as severe as that produced by the $\mathrm{H}^{+} \mathrm{A}^{+}$lesion (Meunier et al., 1993).

Taken together, these data point to the considerable importance to memory functions of the perirhinal and parahippocampal cortices (see Zola-Morgan and Squire, 1993; Mishkin and Murray, 1994, for recent reviews of this conclusion). Moreover, it is clear that these cortical regions are functioning not just as relays for exchanging information between the neocortex and the hippocampal formation, but are carrying out necessary mnemonic processing on their own. There are now three pieces of evidence in support of this idea. First, the memory impairment produced by $\mathrm{H}^{+}$lesions (lesions of the hippocampal formation, parahippocampal cortex, and posterior entorhinal cortex) was increased by extending the lesion forward to include anterior entorhinal cortex and perirhinal cortex (the $\mathrm{H}^{++}$lesion) (ZolaMorgan et al., 1993). Second, PRPH lesions produced more scvere memory impairment than $\mathrm{H}^{+}$lesions (Zola-Morgan et al., 1989b, 1994; Suzuki et al., 1993). Third, PRPH lesions impaired memory more than our $\mathrm{E}$ lesions and more than the entorhinal lesions studied by Meunier et al. (1993).
One possible concern about this conclusion is that the perirhinal and parahippocampal cortices retain direct projections to the hippocampus and subiculum, in addition to their prominent projection to entorhinal cortex (Suzuki and Amaral, 1990). Accordingly, one might suppose that these cortical areas could support memory functions hy either one of these two projections, such that separate $\mathrm{E}$ or $\mathrm{H}$ lesions would not disrupt memory functions as much as PRPH lesions. It would therefore be useful to study monkeys with a complete hippocampal formation lesion $(\mathrm{H}+\mathrm{E})$. If the perirhinal and parahippocampal cortices are carrying out mnemonic functions on their own, then the $\mathrm{H}+\mathrm{E}$ lesion could impair memory more severely than either $\mathrm{H}$ or $\mathrm{E}$ lesions alone, but should, nevertheless, impair memory less severely than PRPH lesions. One indication that this outcome would be obtained comes from the fact cited earlier that the $\mathrm{H}^{+}$ lesion (which included both the hippocampus and posterior entorhinal cortex) impaired memory less than when perirhinal damage was added to the $\mathrm{H}^{+}$lesion (Zola-Morgan et al., 1993, 1994).

\section{Transient nature of the memory impairment}

Perhaps the most surprising finding of the present study was that the memory impairment of the E group was transient. Six to 13 months after completing DNMS-I, the E group relearned DNMS-II normally and obtained delay scores that were indistinguishable from those of normal control monkeys (Fig. 12). Specifically, the E group improved across the two DNMS administrations and the $\mathrm{N}$ group remained stable. On average, the E monkeys scored $15 \%$ higher at the $10 \mathrm{~min}$ and $40 \mathrm{~min}$ retention intervals. Transient memory impairment has not been observed after lesions of other medial temporal lobe regions (ZolaMorgan et al., 1989a,b, 1992; Suzuki et al., 1993), including lesions limited to the hippocampal region (Fig. 12 and Alvarez et al., in press). It should be emphasized that the transient memory impairment in the E group cannot be attributed to the severity of the initial memory performance because hippocampal lesions impaired memory less severely than $E$ lesions but, nonetheless, produced persisting impairment (Zola-Morgan et al., 1994).

Whether there was a neuroanatomical substrate for the behavioral plasticity is presently unclear. We attempted to assess whether the perirhinal cortex made new, lesion-induced connections that might account for the recovery of normal DNMS performance. Because the perirhinal cortex itself is crucially involved in DNMS performance (Meunier et al., 1993), and because lesion-induced axonal sprouting is a well documented phenomenon in the rodent hippocampal system (Cotman and Lynch, 1976), we reasoned that one possible anatomical substrate for functional recovery might be the axonal sprouting of direct perirhinal cortical projections into the dentate gyrus. In the four $\mathbf{E}$ monkeys in which anterograde tracer injections were localized in area 36 of the perirhinal cortex, there was no evidence of novel perirhinal projections to the dentate gyrus. There was, however, a significant expansion of the normal perirhinal-to-hip-

Figure 11. Camera lucida drawings of terminal field labeling at three rostrocaudal levels of the hippocampal formation after ${ }^{3} \mathrm{H}$-amino acids injection in medial area 36; neuroanatomical control monkey (left) and entorhinal lesioned monkey (right). Sections are arranged from rostral (top) to caudal (bottom) and represent matched levels for the control animal and $\mathrm{E}$ animal. Gray shading in C.A 1 shows the stratum lacunosum-moleculare, and black shading indicates the location of the perirhinal terminal field within CA1. Numbers denote the transverse length of the terminal field and stratum lacunosum-moleculare. Note the consistent expansion of the perirhinal terminal field in CAl of the entorhinal-lesioned animal. Additional abbreviations: $C A 1, C A 2, C A 3$, fields of the hippocampus; $D G$, dentate gyrus; slm, stratum lacunosum-moleculare; sr, stratum radiatum; $S$, subiculum. Scale bar, $1 \mathrm{~mm}$. 

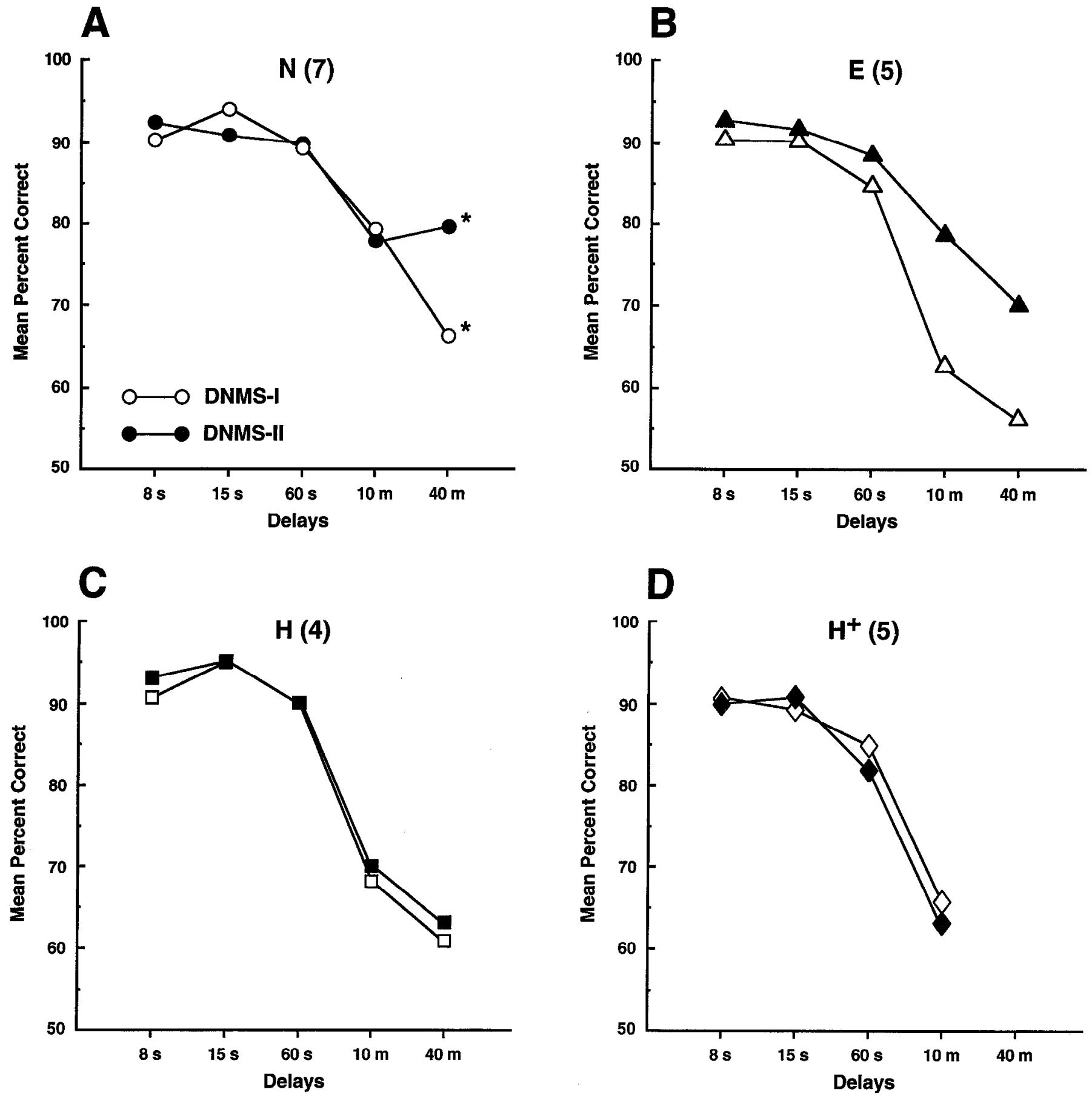

Figure 12. Average delay performance on the first test (open symbols) and the retest ( filled symbols) of DNMS for normal control monkeys $(N)$, monkeys with bilateral lesions of the entorhinal cortex $(E)$, monkeys with bilateral lesions of the hippocampal region $(H$, data from Alvarez et al., in press), and monkeys with combined bilateral lesions of the hippocampal formation, posterior entorhinal cortex, and parahippocampal cortex ( $H+$, data from Zola-Morgan et al., 1993). The E group was the only group to show complete behavioral recovery on the second test occasion. Numbers in parentheses indicate the number of animals in each group. Asterisks in A indicate that only four animals (N1-N4) received testing at the 40 min delay. $\mathrm{H}+$ animals were not tested on the 40 min delay.

pocampal terminal field into more proximal levels of CAl. To our knowledge, this is the first demonstration of lesion-induced sprouting of the nonhuman primate perforant path projection. If the sprouted fibers contact CA1 pyramidal cells in their zones of termination, then CA1 cells that are not normally innervated by the perirhinal cortex would establish new connections. Whether this enhancement of the normal projection to $\mathrm{CAl}$ was involved in the behavioral recovery, however, cannot presently be determined. One might hypothesize that a selective lesion of the CAl region in the long-term $\mathrm{E}$ animals might reinvoke a DNMS deficit if the perirhinal-to-CA1 projection is being utilized to mediate performance on the task. On the other hand, one might predict little or no change in behavior if the sprouted perirhinal-to-CA1 projection is irrelevant to performance of the task. 
In summary, the present findings suggest that the entorhinal cortex may normally participate in the learning and performance of tasks that are dependent on the medial temporal lobe memory system. At the same time, however, these and other recent findings (Mishkin and Murray, 1994) further question the hypothesis that the hippocampal formation is the primary mediator of visual recognition memory function and support the conclusion that the perirhinal and/or parahippocampal cortices play a more prominent role than previously appreciated.

\section{References}

Alvarez P, Zola-Morgan S, Squire LR (in press) Damage limited to the hippocampal region produces long-lasting memory impairment in monkeys. J Neurosci, in press.

Alvarez-Royo P, Clower RP, Zola-Morgan S, Squire LR (1991) Stereotaxic lesions of the hippocampus in monkcys: determination of surgical coordinates and analysis of lesions using magnetic resonance imaging. J Neurosci Methods 38:223-232.

Amaral DG, Cowan, WM (1980) Subcortical afferents to the hippocampal formation in the monkey. J Comp Neurol 189:573-591.

Amaral DG, Insausti R, Cowan WM (1987) The entorhinal cortex of the monkey: I. Cytoarchitectonic organization. J Comp Neurol 264: 326-355.

Harlow H, Bromer JA (1938) A test apparatus for monkeys. Psychol Rev 19:434-438.

Hartley LH, Roger R, Nicolosi RJ, Hartley T (1984) Blood pressure values in Macaca fascicularis. J Med Primatol 13:183-189.

Insausti R, Amaral DG, Cowan WM (1987) The entorhinal cortex of the monkey. II. Cortical afferents. J Comp Neurol 264:356-395.

Kosel K, Van Hoesen GW, Rosene DL (1983) A dircet projection from the perirhinal cortex (area 35) to the subiculum in the rat. Brain Res. 269:347-351.

Meunier M, Bachevalier J, Mishkin M, Murray EA (1993) Effects on visual recognition of combined and separate ablations of the entorhinal and perirhinal cortex in rhesus monkeys. J Neurosci 13:54185432 .

Milner B (1972) Disorders of learning and memory after temporal lobe lesions in man. Clin Neurosurg 19:421-446.

Mishkin M (1978) Memory in monkeys severely impaired by combined but not separate removal of amygdala and hippocampus. Nature 273:297-298.

Mishkin M, Murray, EA (1994) Stimulus recognition. Curr Opin Neurobiol 4:200-206.

Murray EA (1992) Mcdial temporal lobe structures contributing to recognition memory: the amygdaloid complex versus rhinal cortex. In: The amygdala: neurobiological aspects of emotion, memory, and mental dysfunction (Aggleton JP, ed), pp 453-470. London: WileyLiss.

Murray EA, Mishkin M (1984) Severe tactual as well as visual memory deficits follow combined removal of the amygdala and hippocampus in monkeys. J Neurosci 4:2565-2580.

Scoville WB, Milner B (1957) Loss of recent memory after bilateral hippocampal lesions. J Neurol Neurosurg Psychiatry 20:11-21.

Squire LR, Zola-Morgan S (1991) The medial temporal lobe memory system. Science 253:1380-1386.

Suzuki W, Amaral DG (1990) Cortical inputs to the CA1 field of the monkey hippocampus originate from the perirhinal and parahippocampal cortex but not from arca TE. Neurosci Lett 115:43-48.

Suzuki W, Amaral DG (1994a) Topographic organization of the recip- rocal connections between the monkey entorhinal cortex and the perirhinal and parahippocampal cortices. J Neurosci 14:1856-1857.

Suzuki W, Amaral DG (1994b) The perirhinal and parahippocampal cortices of the monkey: cortical afferents. J Comp Neurol 350:497533.

Suzuki W, Zola-Morgan S, Squire L R, Amaral DG (1993) Lesions of the perirhinal and parahippocampal cortices in the monkey produce longlasting memory impairment in the visual and tactual modalities. J Neurosci 13:2430-2451.

Szabo J, Cowan WM (1984) A stereotaxic atlas of the brain of the cynomolgus monkey (Macaca fascicularis). J Comp Neurol 222: $265-300$.

Van Essen DC, Maunsell JHR (1980) Two-dimensional maps of the cerebral cortex. J Comp Neurol 191:225-281.

Van Hoesen GW, Pandya DN (1975a) Some connections of the entorhinal (arca 28) and perirhinal (area 35) cortices of the rhesus monkey. I. Temporal lobe afferents. Brain Res 95:1-24.

Van Hoesen GW, Pandya DN (1975b) Some connections of the entorhinal (area 28) and perirhinal (area 35) cortices of the rhesus monkey. III. Efferent connections. Brain Res 95:39-59.

Van Hoesen GW, Pandya DN, Butters N (1975) Some connections of the entorhinal (area 28) and perirhinal (area 35) cortices of the rhesus monkey. II. Frontal lobe afferents. Brain Res 95:25-38.

Victor M, Agamanolis D (1990) Amnesia due to lesions confined to the hippocampus: a clinical-pathologic study. J Cognit Neurosci 2:246-257.

Witter MP, Amaral DG (1991) Entorhinal cortex of the monkey: V. Projections to the dentate gyrus, hippocampus and subicular complex. J Comp Neurol 307:437-459.

Witter MP, Van Hoesen GW, Amaral DG (1989) Topographical organization of the entorhinal projection to the dentate gyrus of the monkey. J Neurosci 9:216-228, 1989.

Zola-Morgan S, Squire LR (1984) Preserved learning in monkeys with medial temporal lobe lesions: sparing of motor and cognitive skills. J Neurosci 4:1072-1085.

Zola-Morgan S, Squire LR (1985) Medial temporal lobe lesions in monkeys impair memory on a variety of tasks sensitive to human amnesia. Behav Neurosci 99:25-38.

Zola-Morgan S, Squire LR (1993) Neuroanatomy of memory. Annu Rev Neurosci 16:547-563.

Zola-Morgan S, Squire LR, Amaral DG (1986) Human amnesia and the medial temporal region: enduring impairment following a bilateral lesion limited to field CAl of the hippocampus. J Neurosci 6:2950-2967.

Zola-Morgan S, Squire LR, Amaral DG (1989a) Lesions of the amygdala that spare adjacent cortical regions do not impair memory or exacerbate the impairment following lesions of the hippocampal formation. J Neurosci 9:1922-1936.

Zola-Morgan S, Squire LR, Amaral DG, Suzuki W (1989b) Lesions of perirhinal and parahippocampal cortex that spare amygdala and hippocampal formation produce severe memory impairment. J Neurosci 9:4355-4370.

Zola-Morgan S, Squire L R, Remple NL, Clower RP, Amaral DG (1992) Enduring memory impairment in monkeys after ischemic damage to the hippocampus. J Neurosci 12:2582-2596.

Zola-Morgan S, Squire LR, Clower RP, Rempel NL (1993) Damage to the perirhinal cortex exacerbates memory impairment following lesions to the hippocampal formation. J Neurosci 13:251-265.

Zola-Morgan S, Squire L R, Ramus, S (1994) Severity of menory impairment in monkeys as a function of locus and extent of damage within the medial temporal lobe memory system. Hippocampus 4:483-495. 